\title{
A Case Review of an 8-Year-Old Boy with Autistic Syndromic Complex Disorder
}

\author{
«haron Jieren Wong: Twinkle Intervention Center, Singapore. \\ Guohui Xie: Disability \& Disorder Diagnostic Clinic (DDDC), KL, Malaysia.
}

\begin{abstract}
This is a case review of an 8+ year-old boy diagnosed with autistic disorder when he was 3 years old. The aim of this paper is to re-examine the case to find out if there were any other comorbid conditions besides the autism that the boy had been diagnosed. In order to do it, the authors used the diagnostic model based on the hierarchy of the six building blocks of skills and abilities (Chia, 2008; 2012). This is a cross-battery assessment involving several standardized tests and checklists to be carried out. The results provide a new perspective that helps educational therapists and early interventionists to better understand and also to re-consider their treatment approach in helping the child with syndromic complex condition of autistic disorder to cope with his current learning and behavioral challenges.
\end{abstract}

Key words: Autistic Disorder, Cross-battery assessment, Hyperlexia, Pleiotropy.

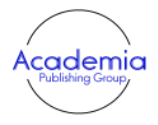

International Journal of Educational Studies Vol. 2, No. 1, pp. 13-35

2019

DOI: $10.53935 / 2641-533 x \cdot v 2 i 1.22$

Corresponding Author: Sharon Jieren Wong

Email:wisharon@gmail.com

Funding: This study received no specific

financial support.

Acknowledgement: The authors wish to thank the parents of CT for their kind permission to use and share the assessment results in this paper. Article History:

Received: 5 December 2018

Revised: 31 December 2018

Accepted: 16 January 2019

Published: 13 February 2019

(C) 2019 by the authors; licensee Academic

Publishing Group

\section{Introduction}

Autism is never a simple disorder per se. By using the term autism spectrum disorders (ASD) "to characterize the condition, the disorder is not a single disorder but many" (Reber, 2012). Nosologically speaking, this is a one-to-many disorder and the term used here to describe is "splitter" or pleiotropy (see McKusick, 1969, for detail). Pleiotropy (also spelled pleiotropism) is one of the two leading principles in genetic nosology; the other being genetic heterogeneity. The term pleiotropy (or "one-to-many" principle) refers to the multiple effects of a single etiologic factor, i.e., it takes place when a gene affects two others or more apparently unrelated phenotypic traits. This gene that manifests a multiple phenotypic expression is known as pleiotropic gene.

From the beginning of the second decade of the twenty-first century, there is a steady acceleration of genetic studies (e.g., Iossifov et al., 2012; O'Roak et al., 2011; Sandars et al., 2012) that continue to make new discoveries on the number of genes predicted to carry risk for ASD, and now, it is reaching well into tens of thousands. According to State and Sestan (2012), "[T]his 'one-to-many' phenomenon, combined with the biological pleiotropy of genes that have so far been implicated in ASD and the presence of core phenotypes that are distinctly human, such as impairments in language development, make the study of ASD in model organisms especially challenging" (p.1301). It is important to note that pleiotropy is the usual, though not sole, basis for hereditary syndromes like ASD. As a clinically and etiologically heterogeneous condition, ASD shares "a triad of unique and severe deficits in social interaction, difficulties in verbal and nonverbal communication, and a restricted repertoire of interests and behaviors" (Reber, 2012).

The pleiotropic relationship of genes, according to State and Sestan (2012), suggests that future studies will have to go beyond isolated molecular dissections of single mutations of genes. From recent genetic 
studies (e.g., Iossifov et al., 2012; O’Roak et al., 2011; Sandars et al., 2012), one surprising and conceptually challenging observation made is the considerable overlap of risks for distinct disorders. "Identical highly penetrant variants in different individuals carry large effects but for a wide range of outcomes, including, but likely not limited to, ASD, epilepsy, intellectual disability, and schizophrenia" (State \& Sestan, 2012). While it is not within the scope of this paper to delve on this topic of interest, it points to the high probability of other disabilities and disorders comorbid to ASD. It is for this reason that the authors have taken a keen interest to find out these comorbidities in autism based on a case review of a boy with high-functioning autistic disorder (HFAD).

\section{A Brief Literature Review}

Over the past decades, the world has seen an increase in the prevalence of autism spectrum disorder (ASD), or autism for short, in many countries from the West through the Middle East, the Far East and SouthEast to the Down Under, i.e., Australia and New Zealand. This has become a worrying trend, especially for educators and parents, and more boys than girls have been affected with the disorder (Chua \& Chia, 2017). In fact, according to Yuhas (2017), it has been suggested that the relatively high autism prevalence in the population can be the result of misdiagnoses of early signs of schizophrenia. As a result, many countries such as Australia, Canada, the United States and the United Kingdom have increased funding for research, treatment, screening, public education and support services for people with autism or ASD (Reber, 2012).

As mentioned earlier in the Introduction, given the heterogeneity of ASD, it is important that there should be some consensus on how to define and classify ASD. The operating definition of autism or ASD has been changing over the past decades from its original concept first developed by Bleuler in 1911 (Camulli \& Goh, 2018). The original understanding of autism is that it was then a symptom of schizophrenia. According to Bleuler (1911), autism is a symptom related to the psychopathology of dementia praecox (Kraepelin, 1887a, $1887 \mathrm{~b}$ ) or the group of schizophrenias with primary symptoms in the disturbances of associations, affect, ambivalence and autistic isolation. However, the term autism or ASD is understood quite differently by today's definition.

In this paper, the authors have chosen to accept the definition of ASD as "a neuro-developmental syndrome of constitutional origin (genetic) and whose cause could also be epigenetic, and its onset is usually around first three years of birth, with empathizing or mentalizing deficits that result in a triad of impairments in communication, social interaction, and imagination, with manifestation of repetitive stereotyped behaviors, but may, on the other hand, display (especially by autistic savants) or hide (especially by autistic cryptosavants) a strong systemizing drive that accounts for a distinct triad of strengths in good attention to detail, deep narrow interests, and islets of ability" (Chia, 2012). This definition allows inclusion of any possible comorbidities to ASD. Hence, the authors prefer the readers to take this definition as the common understanding of what ASD is throughout this paper.

It is not within the current theme of this paper to delve on the changing definition of autism or ASD as there are already many published papers on this topic by established research institutions and organizations, such as the World Health Organization, the US-based National Institute of Mental Health and the US Centers for Disease Control and Prevention, to name just three. For more information on ASD, interested readers can always visit the respective websites of these three organizations or refer to the Diagnostic and Statistical Manual of Mental Disorders (DSM-5; American Psychiatric Association/APA, 2013).

On the first of December 2012, the American Psychiatric Association board of trustees met to approve changes to diagnostic criteria for autism and it has eliminated the diagnosis of Asperger Syndrome. There are also changes in the criteria for the autism diagnosis. With the publication of the fifth edition of the Diagnostic and Statistical Manual of Mental Disorders (DSM-5; American Psychiatric Association, 2013), one of the most significant changes to be made is that the previous diagnostic labels/codes of Autistic Disorder, Asperger Syndrome and Pervasive Developmental Disorder-Not Otherwise Specified (PDD-NOS) are replaced by one umbrella term: Autism Spectrum Disorder (ASD). In addition, ASD will be evaluated according to severity levels of the condition and it includes the amount of support required to meet the challenges of impairments in social communication, restricted interests and repetitive behaviors. Hence, an individual will now be diagnosed with ASD Level 1 (i.e., requiring support), Level 2 (i.e., requiring substantial support) or Level 3 (i.e., requiring very substantial support) depending on the degree of severity (see Camulli \& Goh, 2018, for detail). The reasons given by the American Psychiatric Association are twofold: Firstly, the former way of

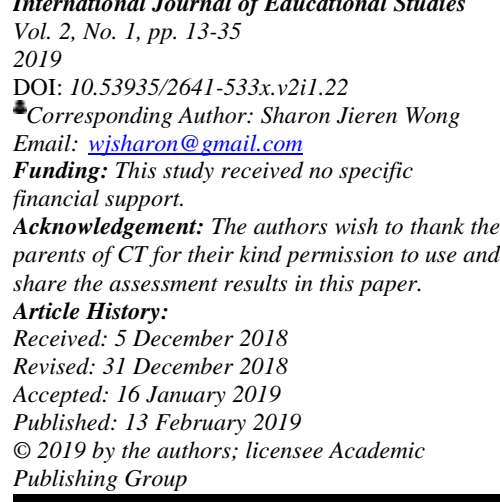


autism diagnosis is not precise enough resulting in the same individual having different disorders when seen by different clinicians as well as changes in the diagnosis from year to year. Secondly, autism should be defined by a common set of behaviors and characterized by a single term according to its levels of severity.

In other words, all the different types of autism, i.e., Autistic Disorder, Asperger's Disorder, and Pervasive Development Disorder-Not Otherwise Specified, are no longer listed as separate but related disorders under the previous DSM-IV-TR (APA, 2000) broad diagnosis of Pervasive Development Disorders. Today, they are subsumed within ASD in the DSM-5 (APA, 2013). In cases where higher functioning individuals do not show all of the requisite criteria for the ASD diagnosis, these are now reclassified under Social Communication Disorder (Lai, Lombardo, Chakrabarti, \& Baron-Cohen, 2013).

Generally, there are three other nosological terms relevant to and frequently used in the diagnosis and classification of ASD: primary, secondary, and syndromic autism. The last two terms - secondary and syndromic - are about the same and refer to "the occurrence of ASD in an individual with a medical condition or syndrome that is assumed to be the cause of the autism" (Reber, 2012). Primary autism - also known as essential autism (Melillo, 2012) - happens in an individual who does not have an identified, purportedly causative medical condition. There is one more term frequently used in autism research: broad autism phenotype. It refers to the traits in relatives of an autistic individual that are qualitatively similar to autistic symptoms, but are not severe enough to confer an ASD diagnosis.

In view of what has been described in this section, it is in the authors' interest as well as within the scope of this paper to examine the nosology of ASD in a case review of an 8+ year-old boy diagnosed with autistic disorder when he was three years of age. The aim was to find out if there were other co-morbidities in his current autistic condition and suggest appropriate ways of treating these problems.

\section{Background Information about the Case}

CT, a boy of Chinese descent, currently aged 9 years, is the older of two siblings in the family. He has a younger sister two years younger. CT was born at 39-week gestation via forceps delivery. His birth weight at the time of delivery was recorded as $2890 \mathrm{~g}$. It was an unremarkable birth and the newborn passed his neonatal hearing screen.

According to his medical records provided by his parents, CT met his motor developmental milestones within normal limits. He sat unsupported at 6 months, walked at 12 months, and climbed stairs at about 18 months of age. However, it was noted that his speech-language development was delayed. According to his speech therapist, the child spoke his first word "milk" at 24 months and combines words (e.g., red Elmo, black car) and knew several words at 30 months old, but he had difficulties using them to communicate meaningfully and appropriately with his parents.

It was reported that CT's paternal uncle had been diagnosed with hebephrenic schizophrenia when the latter was 17 years old. CT's parents suspected that there would be an overlapping link between CT's autistic condition and his uncle's psychotic condition. According to Dvir and Frazier (2011), there is some kind of biological and clinical link between ASD and schizophrenia and this has been supported by several studies (e.g., Ellis et al., 2016; Rapaport et al. 2009; Volkmar \& Cohen, 1991).

However, according to Vorstman et al (2017), ASD and schizophrenia - associated with 22q11.2 deletion syndrome - are found to be two unrelated, distinct phenotypic manifestations, consistent with true neuropsychiatric pleiotropy. Another recent study done by Fiksinski et al. (2017) also indicates that in children with 22q11 deletion syndrome, early childhood autistic features are not associated with an increased risk for subsequent development of psychotic disorders (e.g., schizophrenia) or symptoms. Their findings suggest that ASD and psychotic disorders can emerge independently, as pleiotropic phenotypes in the context of 22q11DS. In other words, although ASD and schizophrenia may share the same pleiotropic gene, they develop into two independent outcomes (Yuhas, 2017).

When CT was 3 years old, his parents sent him to a public hospital for an assessment to be done due to concerns with his communication, social interaction and stereotyped behavior. A parent interview was carried out by a psychologist and it was followed with the administration of the Autism Diagnostic Observation Schedule (ADOS; Di Lavore, Lord, \& Rutter, 1995) Module 1 on the same day. The ADOS is a semistructured, standardized assessment of four domains, i.e., social interaction, communication, play, and imaginative use of materials, for individuals suspected of having ASD. Its observational schedule consists of four 30-minute modules. Each module is designed to be administered to an individual according to his/her

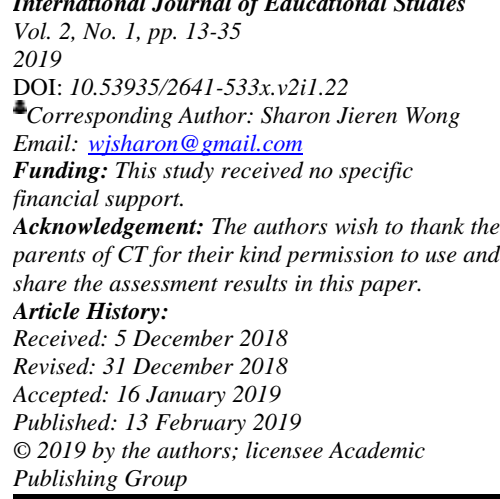




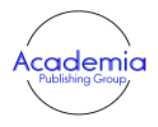

International Journal of Educational Studies Vol. 2, No. 1, pp. 13-35

2019

DOI: $10.53935 / 2641-533 x . v 2 i 1.2$

Corresponding Author: Sharon Jieren Wong

Email:wisharon@gmail.com

Funding: This study received no specific

financial support.

fhe authors wish to thank the

parents of CT for their kind permission to use and

share the assessment results in this paper.

Article History:

Received: 5 December 2018

Revised: 31 December 2018

Accepted: 16 January 2019

Published: 13 February 2019

(C) 2019 by the authors; licensee Academic

Publishing Group level of expressive language. Based on the ADOS algorithm, CT met the classification criteria for autism or autistic disorder.

According to the parent interview, it was noted that CT had an unusual interest in numbers and words than pictures since young. When he was 2 years 3 months old, he would bring his magna doodle board to his parents and ask them to spell words for him. This went on everyday over two to three months during which he engaged in a verbal routine of counting. He continued to love reading out numbers and words he saw them (e.g., on lift signage, road signposts, etc.). He also sought out YouTube videos containing numbers. He could count from 1 to 100 forward and backward with ease. Since three years-old, he could count in multiples of up to 12 . He showed an unusual attraction for numbers suggesting he had numerophilia ${ }^{l}$. Sometimes, he would expect others to continue counting where he left off, and would sometimes insist his parents to count together with him. CT could also recite the 26 letters in the English Alphabet forward and backward! His obsession with letters and words suggested he had lexicophilia ${ }^{2}$ - an unnatural attraction for letters and words. CT continues to exhibit these awesome feats even today. These unusual attractions for numbers and/or letters/words are also classical signs of hyperlexia - "a syndrome characterized by an intense fascination with letters or numbers and an advanced reading ability" (Bainbridge, 2018, para.4). Children with hyperlexia often begin reading when they are very young, as early as two years old, and they can read at levels far beyond what is expected at their age. They can read very well without any prior reading instruction (Worthy \& Invernizzi, 1995).

\section{Diagnostic Assessments and Results}

A series of standardized tests and checklists were administered to provide an updated status of CT's autistic condition. These tests follow the Hierarchy of Building Blocks of Skills and Abilities postulated by Chia $(2008,2012)$ as a framework for cross-battery assessment (X-BA for short). This X-BA approach emphasizes the use of data obtained from multiple test batteries in guiding the diagnostic decision to gain a fuller picture of CT's cognitive abilities than can be ascertained through the use of single-battery assessments (Flanagan \& McGrew, 1997).

There is a difference between the two terms - skills and abilities - used in the paragraph above. In fact, skills are abilities. However, a skill is a composite of abilities, techniques and knowledge (DB.net, 2018; Julita, 2011). They are the ones that make a person do tasks at a higher degree or standard with goal-oriented expectations of improvements or positive changes in an individual's performance. DB.net (2018) and Julita (2011) have provided a brief summary of skills and abilities:

1. A skill is acquired. On the other hand, an ability is more of constitutional origin or inherited.

2. A skill can be practiced to perfection but not the ability, which an individual either possesses or not. For instance, talent is an ability, not a skill.

3. As a skill is goal-directed, it expects an individual to attain a higher level of performance. However, unlike the skill, an ability does not necessarily equate to exceptional performance.

4. An individual's level of functionality depends more on ability than skill.

5. An ability is more stable than a skill.

Whether a child can perform well academically depends on the hierarchy of skills and abilities as proposed by Chia (2012). There are five building blocks in the hierarchy of skills and abilities. This hierarchical framework follows the ascending order as shown below (see Figure 1):

- Foundation Block of innate abilities (e.g., Wechsler Intelligence Scale for Children-4 $4^{\text {th }}$ Edition/WISC-IV or Slosson Intelligence Test- $4^{\text {th }}$ Edition/SIT-4);

- Block II of sensory perceptual-motor processing and coordination skills and abilities (e.g., Sensory Profile-2 $2^{\text {nd }}$ Edition-Child version/SP-2C);

- Block III of adaptive behavioral skills and abilities (e.g., Vineland Adaptive Behavior Scales-2 ${ }^{\text {nd }}$ Edition/VABS-2 or Adaptive Behavior Diagnostic Scale/ABDS);

\footnotetext{
${ }^{1}$ Numerophilia is an extreme interest in numbers.

${ }^{2}$ Lexicophilia (an extreme interest in letters and/or words) can be a subtype of Bibliophilia which is described as an extreme love or excessive interest in books.
} 
- Block IV of social-emotional skills and abilities (e.g., Screening Assessment for Emotional Disturbance$2^{\text {nd }}$ edition/SAED-2); and

- Block V of cognitive skills and abilities (e.g., Aston Index-Revised/AI-R and Neale Analysis of Reading Ability-2 ${ }^{\text {nd }}$ Edition/NARA-2).

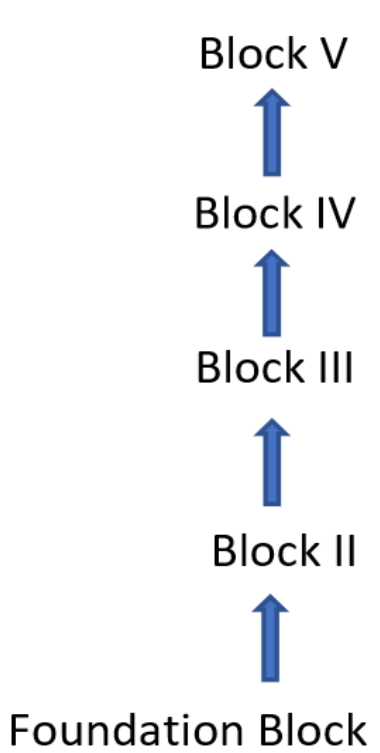

\begin{tabular}{|c|}
\hline $\begin{array}{c}\text { Cognitive } \\
\text { Skills \& Abilities }\end{array}$ \\
\hline $\begin{array}{c}\text { Social-Emotional } \\
\text { Skills \& Abilities }\end{array}$ \\
\hline $\begin{array}{c}\text { Adaptive Behavioral } \\
\text { Skills \& Abilities }\end{array}$ \\
\hline $\begin{array}{c}\text { Sensory Perceptual-Motor } \\
\text { Processing \& Coordination } \\
\text { Skills \& Abilities }\end{array}$ \\
\hline Innate Abilities \\
\hline
\end{tabular}

E.g., Al-R, NRPVT

E.g., DaCT

E.g., ABDS, VABS-2

E.g., SP-2C

E.g., WISC-IV

Figure-1. The Hierarchy of the Building Blocks of Skills and Abilities

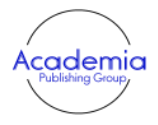

International Journal of Educational Studies Vol. 2, No. 1, pp. 13-35

2019

DOI: 10.53935/2641-533x.v2il.22

Corresponding Author: Sharon Jieren Wong

Email: wjsharon@gmail.com

Funding: This study received no specific

financial support.

Acknowledgement: The authors wish to thank the parents of CT for their kind permission to use and share the assessment results in this paper. Article History:

Received: 5 December 2018

Revised: 31 December 2018

Accepted: 16 January 2019

Published: 13 February 2019

(1) 2019 by the authors; licensee Academic

Publishing Group
According to Chia (2008), the Hierarchy of Building Blocks of Skills \& Abilities has six levels or blocks as briefly described below:

- Foundation Block/Block I refers to the core block of an individual's innate abilities which deal with the use of language to communicate, abstract thoughts and reasoning skills, memory retention as well as problem solving skills. An example of an assessment tool for this level is an IQ test.

- Block II focuses on the sensory-perceptual-motor coordination and related behavioral skills and abilities involving balance/motion of the body (vestibular) and position of body (proprioception). An example of an assessment tool for this level is the Sensory Profile (Dunn, 1999).

- Block III concerns the adaptive behavioral skills and abilities, such as activities of daily living, social interaction, communication, self-help skills (e.g., toileting, dressing, bathing), personal hygiene and other related practical skills. An example of an assessment tool for this level is the Adaptive behavior Diagnostic Scale (Pearson, Patton, \& Mruzek, 2016).

- Block IV consists of socio-emotional behavioral skills and abilities which cover adaptive, internalizing and externalizing behavioral skills. This level of skills and abilities can also be determined by assessment tools such as Sensory Profile (Dunn, 1999) done at level \#2.

- Block V focuses more on academic or educational attainments, which include higher levels of cognition, involving word knowledge (i.e., active and passive vocabularies), general knowledge, ability to count and perform operational functions involving numbers and ability to carry out activities using both verbal and nonverbal reasoning skills. Most of the assessment tools are academic attainment measures, such as Neale Analysis of Reading Ability-2 $2^{\text {nd }}$ Edition, Schonell Graded Reading and Spelling Tests and Word Recognition Test.

- Block VI concerns with the ability to listen, understand and execute verbal instructions, and often such skills and abilities are dependent on an individual's learning style.

\subsection{Foundation Block of Innate Abilities}

- Wechsler Preschool and Primary Scale of Intelligence-4 ${ }^{\text {th }}$ Edition (WPPSI-IV)

Chronological Age (at the time of testing): 5:04 
The Wechsler Preschool and Primary Scale of Intelligence- $4^{\text {th }}$ Edition (WPPSI-IV; Wechsler, 2003) is a standardized measure of intellectual functioning of children aged 2 years 6 months to 7 years 7 months. It assesses a child's cognitive ability across five areas: verbal comprehension, visual-spatial, fluid reasoning, working memory and processing speed. It gives a total score known as Full-Scale Intelligence Quotient (FSIQ) that represents the child's overall intellectual/cognitive ability. No quantitative or standard scores of the WPPSI-IV indexes or subtests was provided. The psychological report gave only a qualitative description on how CT had performed in the assessment. CT's FSIQ was in the extremely low range at 1\%ile rank and indicated that his overall intellectual functioning was poorly developed as compared to the peers of his age. Tables 1 and 2 below provide a general description of the results CT had obtained in the WPPSI-IV assessment.

Table-1. The WPPSI-IV Core Index Cores

\begin{tabular}{llcc}
\hline & \multicolumn{1}{c}{ WPPSI-IV Core Indexes } & Descriptor & Percentile Rank \\
\hline 1. & Verbal Comprehension Index (VCI) & Extremely Low $(<69)$ & $0.3 \%$ ile \\
2. & Visual Spatial Index (VSI) & Low Average $(80-89)$ & $13 \%$ ile \\
3. & Fluid Reasoning Index (FRI) & Borderline $(70-79)$ & $3 \%$ ile \\
4. & Working Memory Index (WMI) & Low Average $(80-89)$ & $12 \%$ ile \\
5. & Processing Speed Index (PSI) & Extremely Low $(<69)$ & $1 \%$ ile \\
6. & Full-Scale Intelligence Quotient & Extremely Low $(<69)$ & $1 \%$ ile \\
\hline
\end{tabular}

The With an overall intellectual functioning in the extremely low range ( $<69$ at $1 \%$ ile rank), CT was in the category of intellectual disability when he was a preschooler. His performance in both VCI and PSI was in the extremely low range (standard score is 69 or less). The VCI measures the ability to acquire knowledge from the environment and it includes verbal concept formation and verbal reasoning. With extremely low VCI results, CT's verbal comprehension skills were exceptionally weak as compared to his peers. It indicated the child's incapacity to acquire, retain and retrieve general factual knowledge. His verbal concept formation and abstract reasoning were very poorly developed. The PSI measures the ability to quickly and accurately scan or discriminate simple visual information. Moreover, it also measures short-term memory, visual-motor coordination, cognitive flexibility, visual discrimination, concentration, and rate of test-taking. CT's poor PSI results indicated that his visual short-term memory, visual discrimination skills and visual recognition skills were poorly developed. CT's performance in the FRI was in the borderline range (70-79). The FRI measures a child's fluid and inductive reasoning ability, broad visual intelligence, simultaneous processing, conceptual thinking and classification ability. His weak FRI score indicated that CT's categorical reasoning and perceptual organization were poor. CT's performance in both VSI and WMI was in the low average range (80-89). The VSI assesses the ability to organize visual information, understand part-whole relationships, pay attention to visual detail, and integrate visual and motor functions. His low average performance suggested that CT had poor ability to analyze and synthesize abstract visual information and he also struggled to understand part-whole relationships and engage in trial-and-error learning. The WMI measures specific aspects of working memory (e.g., visual working memory and visual-spatial working memory), ability to resist interference from previously memorized items (i.e., to resist proactive interference). This involves attention, concentration, mental control and reasoning. CT demonstrated poor ability to remember a given series of rapidly-presented items. He was also poor in remaining attentive during interactive tasks or when information was supplemented by spatial cues.

In addition, Table 2 shows the results of two WPPSI-IV ancillary indexes

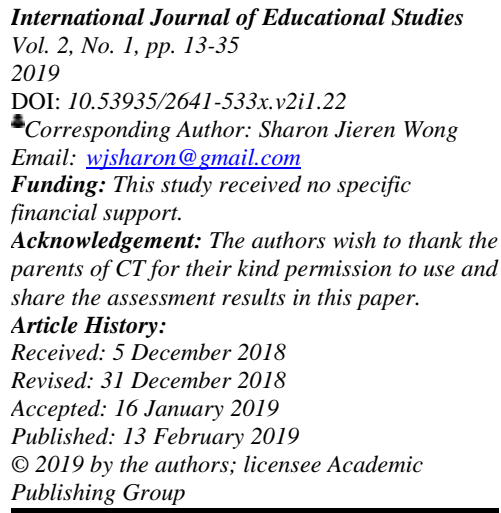

Table-2. The WPPSI-IV Ancillary Index Scores

\begin{tabular}{llcc}
\hline & WPPSI-IV Ancillary Indexes & Descriptor & Percentile Rank \\
\hline - & Vocabulary Acquisition Index (VAI) & Borderline (70-79) & $7 \%$ ile \\
- Nonverbal Index (NVI) & Borderline (70-79) & $3 \%$ ile \\
\hline
\end{tabular}

In both VAI and NVI performance, CT's scores were in the borderline range (70-79). The VAI provides an estimate of a child's vocabulary acquisition based on receptive and expressive vocabulary skills. CT's word knowledge for both receptive and expressive vocabulary skills were poor as compared to his peers. He was able to present with adequate expressive vocabulary skills but very poor receptive vocabulary skills. The 
NVI provides an estimate of the child's ability to solve problems without the use of language. CT's visualperceptual, abstract reasoning, and problem-solving skills were poorly developed as compared to same-aged peers.

- $\quad$ Pictorial Test of Intelligence-2 ${ }^{\text {nd }}$ Edition (PTI-2)

Chronological Age (at the time of testing): 8:09

The Pictorial Test of Intelligence-2 ${ }^{\text {nd }}$ Edition (PTI-2; Eaves \& Williams, 2005) is designed to identify children who are significantly below their peers in important abilities and to identify children among these who are physically disabled who are more able to think and reason than their traditional communication skills support. The IQ test instrument is objectively scored, individually administered on general intelligence for both normal and disabled children ages 3-0 through 8-11 years.

There are three PTI-2 subtests and they are briefly described below:

a) Subtest 1-Verbal Abstractions (VA): It measures auditory, visual, and mental processing related to verbal knowledge, verbal comprehension, and verbal reasoning.

b) Subtest 2-Figure Discrimination (FD): It determines a child's ability to match forms, differentiate between similar shapes, identify unfinished pictures, find embedded shapes, and reason about abstract shapes and patterns.

c) Subtest 3-Quantitative Concepts $(Q C)$ : It measures a child's ability to perceives and recognize size, comprehend number symbols, count, solve simple arithmetic problems. Higher order thinking is usually required. Problems are phrased to measure understanding and use of quantitative facts usually learned at an early age.

The PIQ (Pictorial Intelligence Quotient) is the composite score derived from the PTI-2 administration. It is derived by combining the standard scores of VA, FD and QC subtests. It is the best estimate of Spearman global factor $(\mathrm{g})$ in that it reflects status on the widest array of abilities. The PIQ is the most useful value derived from the PTI-2 because it reflects the child's ability relative to the basic constructs built into the test (Eaves \& Williams, 2005).

Table-3. The PTI-2 Results

\begin{tabular}{lccccc}
\hline Subtests & $\begin{array}{c}\text { Raw } \\
\text { Score }\end{array}$ & $\begin{array}{c}\text { Age } \\
\text { Equiv. }\end{array}$ & $\begin{array}{c}\text { \%ile } \\
\text { Rank }\end{array}$ & $\begin{array}{c}\text { Scaled } \\
\text { Score }\end{array}$ & Descriptor \\
\hline Verbal Abstractions (VA) & 16 & $3: 09$ & $<1 \%$ ile & 1 & Very Poor \\
Form Discrimination (FD) & 21 & $8: 09$ & $50 \%$ ile & 10 & Average \\
Quantitative Concepts (QC) & 15 & $6: 00$ & $\begin{array}{c}16 \% \text { ile } \\
\text { \%ile }\end{array}$ & $\begin{array}{c}7 \\
\text { Standard } \\
\text { Rank }\end{array}$ & $\begin{array}{c}\text { Score } \\
\text { Below Average } \\
\text { Descriptor }\end{array}$ \\
Pictorial IQ & & & & \\
& & & $4 \%$ ile & 74 & Poor \\
\hline
\end{tabular}

Table 3 above shows CT's scores for the three PTI-2 subtests. He performed very poorly in his Verbal Abstractions (VA) indicating that he had very poor language skills. His score for Quantitative Concepts (QC) was below average suggesting that he was better in numeracy skills than his language or literacy skills. His score for Form Discrimination (FD) was average indicating his visual-spatial perception was normal like his peers. Children with ASD often display better performance in visual-spatial (as in FD subtest) than auditory/verbal processing (as in VA subtest). With a PIQ of 74 obtained on the PTI-2 administration, CT was identified as a child with high-functioning autistic disorder (HFAD), who has speech, is less likely to suffer from epilepsy, and has an IQ score of 71 or above (Pierangelo \& Giuliani, 2007). Although too much sensory input can overload such children, they possess "a higher tolerance and learn to desensitize themselves" (Pierangelo \& Giuliani, 2007, p.258). Hence, it is not surprising to find such children with HFAD displaying la belle indifference.

\subsection{Block II of Sensory Behavioral Skills and Abilities}

- Sensory Profile-2 ${ }^{\text {nd }}$ Edition-Child Version (SP-2C)

Chronological Age (at the time of testing): 8:09

The Sensory Profile-2 ${ }^{\text {nd }}$ Edition-Child Version (SP-2C; Dunn, 2014) is standardized tool that evaluates a child's sensory processing patterns in the context of daily life. This is a significantly revised 
questionnaire that helps a therapist to determine how sensory processing may be contributing to or interfering with the child's participation in activities of daily living. Its forms can be completed by the primary caregivers and/or the teachers, especially those in the best position to observe the child's response to sensory interactions that occur throughout the day.

This SP-2C Evaluation Report is divided into the following three sections:

a) Section 1: It reports on the child's sensory quadrants in terms of his sensory patterns, what to do and his sensory dispositions for those identified as sensory under-responsivity (SUR) or sensory over-responsivity (SOR). However, in the recent update on the understanding of Sensory Processing (based on Dunn's model) for Infant/Toddler Sensory Profile, under-responsive is not equivalent to less than others, and over-responsive is not equivalent to more than others. "Less than others" simply means that the person does the behaviors listed in that grouping (sections or quadrant groups) less than typical peers. "More than others" simply means that the person does the behaviors listed in that grouping (sections or quadrant groups) more than typical peers. When discussing general sensory responses, the terms under-responsive and over-responsive are still being applied (e.g., Tommy is generally under-responsive to his environment) (Psychological Corporation, 2003).

The Table 4 below shows CT's scores in the SP-2C Section 1 on Sensory Quadrants based on the four main sensory patterns.

Table-4. SP-2C Results on the Quadrants of 4 Sensory Patterns

\begin{tabular}{cccc}
\hline Quadrant & Raw Score/Total & Percentile Range & SUR or SOR $^{3}$ \\
\hline Seeker & $39 / 95[\%]$ & $9-84 \%$ ile & Just like others \\
Avoider & $54 / 100[\%]$ & $87-96 \%$ ile & More than others \\
Sensor & $63 / 95[\%]$ & $9-86 \%$ ile & SOR \\
Bystander & $66 / 110[\%]$ & $97-99 \%$ ile & SOR \\
\hline
\end{tabular}

CT has a high indication for two out of the four sensory patterns, i.e., much more than others, for Quadrant 3-Sensor and Quadrant 4-Bystander. With this combination of 2 sensory patterns with much more than others, the child displays sensory over-responsivity (SOR) in the following sensory responses: Sensor: $\quad$ Sensory Pattern: He reacts more quickly and more intensely than others.

What to do: To help him regulate this SOR, it is good to provide him structured patterns of sensory experiences in daily tasks.

Sensory Disposition: As a Sensor, the child has a high level of awareness of the environment and attention to detail.

Bystander: Sensory Pattern: He misses more sensory cues than others.

What to do: To help him regulate this SOR, it is important to increase the intensity of sensory experiences in everyday tasks.

Sensory Profile: As a Bystander, the child finds it easier to focus of tasks of interest in a distracting environment where he is in. The child does not detect stimuli that may be distracting to others.

b) Section 2: This section reports on the child's behavioral responses associated with sensory processing in terms of his conduct, social emotional responses and attentional responses.

Table 5 below shows CT's behavioral responses associated with sensory processing in terms of conduct, social emotional responses and attentional responses:

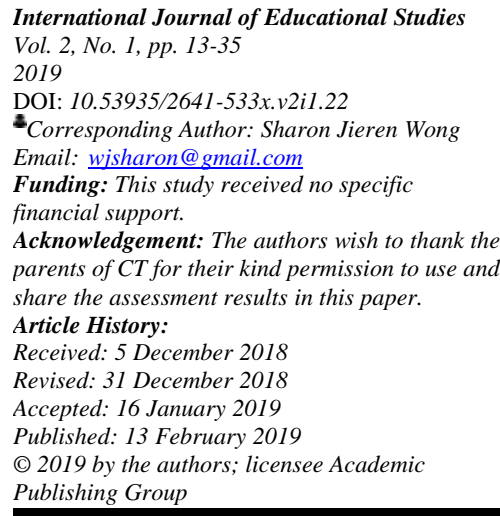

Table-5. The SP-2C Results on Behavioral Responses Associated with Sensory Processing

\begin{tabular}{cccc}
\hline Behavioral Elements & Raw Score/Total & Percentile Range & SUR or SOR \\
\hline Conduct & $21 / 45[44 \%]$ & $6-84 \%$ ile & Just like others \\
Social Emotional & $46 / 70[74 \%]$ & $97-99 \%$ ile & SOR \\
Attentional & $27 / 50[84 \%]$ & $85-93 \%$ ile & More than others \\
\hline
\end{tabular}

\footnotetext{
${ }^{3}$ SUR = Sensory Under-Responsivity (Much less than others); SOR = Sensory Over-Responsivity (Much more than others).
} 
Based on the abovementioned results, CT did not have any conduct problems associated with sensory processing. However, the child displayed much more than others (sensory over-responsivity) for his social emotional responses associated with sensory processing. His attentional response associated with sensory processing was more than others.

As seen in Table 5 above, CT's social emotional responses associated with sensory processing were seen as the only problem, i.e., being much more than others (sensory over-responsivity). In Table 6 below, when taking a step more in-depth in the SP-2C evaluation, all the three behavioral responses associated to sensory processing were found to have low threshold level and produced passive reactions. Only conduct responses associated with sensory processing was found to have both low and high threshold levels. However, the sensory responsivity remained passive. To sum it all, CT displayed a la belle indifference attitude, it seems, in all situations.

Table-6. The SP-2C Behavioral Outcomes of "Much More Than Others" Sensory Responses

\begin{tabular}{|c|c|c|c|c|c|}
\hline \multirow{2}{*}{$\begin{array}{c}\text { Behavioral } \\
\text { Responses to } \\
\text { Sensory Processing }\end{array}$} & \multicolumn{2}{|c|}{ Sensitivity } & \multicolumn{2}{|c|}{ Responsivity } & \multirow{2}{*}{$\begin{array}{c}\text { Behavioral } \\
\text { Outcomes of } \\
\text { Sensory } \\
\text { Responses }\end{array}$} \\
\hline & $\begin{array}{l}\text { Sensor } \\
\text { Avoider } \\
\text { (LOW) }\end{array}$ & $\begin{array}{l}\text { Bystander } \\
\text { Seeker } \\
\text { (HIGH) }\end{array}$ & $\begin{array}{c}\text { Avoider } \\
\text { Seeker } \\
\text { (ACTIVE) }\end{array}$ & $\begin{array}{c}\text { Sensor } \\
\text { Bystander } \\
\text { (PASSIVE) }\end{array}$ & \\
\hline Conduct & $7 / 15$ [47\%] & $14 / 30$ [47\%] & $12 / 30$ [40\%] & $9 / 15$ [60\%] & $\begin{array}{l}\text { Low/Passive or } \\
\text { High/Passive }\end{array}$ \\
\hline Social Emotional & 45/65 [69\%] & $1 / 5[20 \%]$ & $35 / 55$ [64\%] & $11 / 15$ [73\%] & Low/Passive \\
\hline Attentional & $12 / 20[60 \%]$ & $18 / 35$ [51\%] & $3 / 15[20 \%]$ & $26 / 40[65 \%]$ & Low/Passive \\
\hline
\end{tabular}

c) Section 3: It reports on the child's neurological threshold and sensory behavioral responses. There are two parts to this Section 3: (1) Sensitivity refers to the neurological threshold to notice sensory stimuli; and (2) Responsivity refers to sensory behavioral responses to sensory processing.

CT's scores shown in Table 7 below are taken from the different sensory processing (i.e., auditory, visual, touch, movement, body position, and oral) in terms of two main factors - reactivity/sensitivity (i.e., LOW or HIGH) and responsivity (i.e., ACTIVE or PASSIVE) - obtained from the SP-2C administration. A further explanation for these two factors is provided below.

Table-7. SP-2C Results on Neurological Threshold \& Sensory Behavioral Responses

\begin{tabular}{lccccl}
\hline \multicolumn{1}{c}{$\begin{array}{c}\text { Sensory } \\
\text { Processing }\end{array}$} & \multicolumn{2}{c}{ Reactivity/Sensitivity } & \multicolumn{2}{c}{ Responsivity } & \multicolumn{1}{c}{$\begin{array}{c}\text { Sensory } \\
\text { Outcome }\end{array}$} \\
\cline { 2 - 5 } & $\begin{array}{c}\text { Sensor } \\
\text { Avoider } \\
\text { (LOW) }\end{array}$ & $\begin{array}{c}\text { Bystander } \\
\text { Seeker } \\
\text { (HIGH) }\end{array}$ & $\begin{array}{c}\text { Avoider } \\
\text { Seeker } \\
\text { (ACTIVE) }\end{array}$ & $\begin{array}{c}\text { Sensor } \\
\text { Bystander } \\
\text { (PASSIVE) }\end{array}$ & \\
\hline Auditory $_{\text {Visual }^{\mathrm{a}}}$ & $15 / 35[43 \%]$ & $3 / 5[60 \%]$ & $5 / 15[33 \%]$ & $13 / 25[52 \%]$ & High/Passive \\
& $9 / 15[60 \%]$ & $6 / 10[60 \%]$ & $5 / 10[50 \%]$ & $10 / 15[67 \%]$ & $\begin{array}{l}\text { Low/Passive or } \\
\text { high/Passive }\end{array}$ \\
Touch & $7 / 20[35 \%]$ & $14 / 30[47 \%]$ & $7 / 20[35 \%]$ & $14 / 30[47 \%]$ & High/Passive \\
Movement & Not Applicable & $12 / 35[34 \%]$ & $7 / 25[28 \%]$ & $5 / 10[50 \%]$ & High/Passive \\
Body Position & Not Applicable & $25 / 35[71 \%]$ & $5 / 5[100 \%]$ & $20 / 30[67 \%]$ & High/Active \\
Oral & $21 / 25[84 \%]$ & $13 / 20[65 \%]$ & $13 / 20[65 \%]$ & $21 / 25[84 \%]$ & Low/Passive \\
\hline a Visual Processing, item score of AV15 is included. & & & \\
\hline
\end{tabular}

International Journal of Educational Studies Vol. 2, No. 1, pp. 13-35

2019

DOI: $10.53935 / 2641-533 x$ v2il.22

Corresponding Author: Sharon Jieren Won

Email:wjsharon@gmail.com

Funding: This study received no specific

financial support.

gement: The authors wish to thank the parents of CT for their kind permission to use and share the assessment results in this paper. Article History:

Received: 5 December 2018

Revised: 31 December 2018

Accepted: 16 January 2019

Published: 13 February 2019

() 2019 by the authors; licensee Academic

Publishing Group
1. Sensitivity (Neurological Threshold)

LOW $=$ This means quick to notice sensory stimuli.

$\mathrm{HIGH}=$ This means slow to notice sensory stimuli.

CT has LOW sensitivity (neurological threshold) for oral processing which means he is quick to notice or respond to sensory stimuli. However, the child has HIGH sensitivity (neurological threshold) for auditory, touch, movement, and body position which means CT is slow to respond to sensory stimuli involving these sensory processes. Only for visual processing, CT may display either LOW or HIGH sensitivity depending on how he chooses to register the sensory input.

2. Responsivity (Self-Regulating Behavior)

ACTIVE $=$ This means to engage in behaviors to manage or control sensory input.

PASSIVE $=$ This means to allow sensory experiences to happen and then react. 
CT displayed three responsivity patterns which are briefly described below:

a) Responsivity Pattern \#1: CT's HIGH auditory processing, HIGH touch processing, and HIGH movement processing $\rightarrow$ PASSIVE responsivity. In other words, more intense sensory stimulation is required by CT in auditory, touch, and movement processes in order for him to respond to what he is instructed (=auditory) to do.

b) Responsivity Pattern \#2: CT's HIGH body position processing $\rightarrow$ ACTIVE responsivity. The child's body position processing scored the highest in the HIGH neurological threshold (sensitivity). In other words, more intense and rigorous stimulation is required by the child's body position (proprioception) processes in order for him to respond to what is going on. The proprioceptive sense tells CT about his body position. It is stimulated every time he moves. Each time the child uses his muscles or stretches and bends his joints. Receptors for this sense are all over the body, deep within his joints and muscles. Therefore, whenever CT pushes, pulls or lifts heavy things he really stimulates this sense.

In CT's case, at the time of evaluation, the child was observed to be slow to feel or notice sensory stimuli associated with his body position. Unless it was intensely stimulated, CT would not engage in his behavioral response associated with proprioceptive sensory processing. In other words, CT's proprioceptive input must be strongly felt in order that for him to be regulating, calming, soothing, organizing and/or alerting, depending on the current state of his nervous system, which is regulated by the Reticular Activating System (RAS). This system has a major role in the regulation of alertness levels (among other functions). It will enable CT to focus his attention, acting like a filter to dampen down the effect of repeated stimuli. With poor proprioceptive sense, CT would display poor sense of bodily awareness and this problem is often associated with alexithymia. Hence, interventions targeting alexithymia can help to increase emotional coherence that may, in turn, improve the child's socio-emotional communication (Costa, Steffgen, \& Samson, 2017).

Activities that help to stimulate CT's proprioceptive sense: e.g., pushing (for example against the floor in crab, mountain or dog pose); pulling (tug of war, or gently rowing with a partner in boat pose); squeezing (into mouse pose); climbing or lifting; and stretching (e.g. whole body stretch in blooming rose or starfish pose).

3. Responsivity Pattern \#3: CT's LOW oral processing $\rightarrow$ PASSIVE responsivity. In other words, CT is quick to sense taste, smell and temperature of food or what goes into his mouth (e.g., ice-cream) but his behavioral response associated with oral sensory processing is very much passive. Such a child should be verbal but is "too lazy" to talk or interact with others. It can be a sign of preferred sedentary disposition. The child will pass through the sensory experience with short-lived protest unless he senses it as something of a serious threat to him.

\subsection{Block III of Adaptive Behavioral Skills and Abilities}

- Vineland Adaptive Behavior Scales-2 ${ }^{\text {nd }}$ Edition (VABS-2)

Chronological Age (at the time of testing): 5:04

The Vineland Adaptive Behavior Scales-2 $2^{\text {nd }}$ Edition (VABS-2; Sparrow, Cicchetti, \& Balla, 2005) Parent/Caregiver Rating Form is a rating form designed to assess the ability to carry out day-to-day activities necessary to take care of oneself and get along with others. It can be used to help diagnose and evaluate the special needs of children. The focus of the VABS-2 is the standardized measurement of the adaptive behaviors, which includes an individual's ability to cope with environmental changes, to learn new everyday skills and to demonstrate independence.

Although no standard or scaled scores were given, the assessment report provided a qualitative description Vol. 2, No. 1, pp. 13-35

\section{- Adaptive Behavior Diagnostic Scale (ABDS)}

Chronological Age (at the time of testing): 8:10

The Adaptive Behavior Diagnostic Scale (ABDS; Pearson, Patton, \& Mruzek, 2016) is "an interviewbased rating scale that is used to assess adaptive behavior of individuals for ages 2 through 21 years ... [Its] function ... is to establish the presence and magnitude of adaptive behavior deficits" (Pearson, Patton, \& Mruzek, 2016, p.1). The results of the ABDS administration provides both the therapist working with the 
client and the client's parents a better understanding of the client's daily functionality, especially relating to the practical tasks under the category of Daily Living Skills (Bal, 2015).

The ABDS provides information on the following three domains (Pearson, Patton, \& Mruzek, 2016):

1. Conceptual Domain: It measures skills in language, reading, writing, mathematics, reasoning, knowledge, and memory.

2. Social Domain: It measures empathy, social judgment, gullibility, communication skills, the ability to make and retain friendships, and similar interpersonal capabilities.

3. Practical Domain: It measures self-management personal care, home living, community use, job responsibilities, money management, recreation, and organizing school and work tasks.

The above three domains are exactly the three-factor structure of adaptive behavior skills first introduced by Heber (1961) to be included in the definition of mental retardation in the sixth edition of the Manual on Terminology and Classification published by the American Association on Mental Deficiency (AAMD).

Raw scores obtained in the ABDS administration are converted into domain index scores, percentile ranks and age equivalents. An adaptive behavior composite (ABC) index score is computed from the sum of the scores obtained from the three domains. The descriptive terms in terms of the range of standard scores that correspond to domain and composite scores are shown in Table 8 below:

Table-8. Descriptive Terms that correspond to Domains and Composite Scores

\begin{tabular}{cl}
\hline Domain \& Composite Scores & Descriptive Terms \\
\hline$>109$ & Above average \\
$90-109$ & Average \\
$80-89$ & Low average \\
$70-79$ & Low \\
$55-69$ & Very low \\
$<55$ & Extremely low \\
\hline
\end{tabular}

Adaptive behavior describes the typical performance in activities of daily living (ADL). It represents an individual's ability to translate cognitive potential into real-world skills, such as effectively communicating with others, participating in community activities, and developing meaningful relationships (Klin et al., 2007). Several studies (e.g., Farley et al., 2009; Kanne et al., 2011; Pugliese et al., 2015) have indicated that adaptive behavior is more closely related to social functioning and independent living than intellectual ability or ASD symptomatology. However, in CT's case, with a very low adaptive behavior composite (ABC) of 66 at the time of assessment, he had an extremely low score of 44 (at <1\%ile rank) for social domain, which was 22 points behind his $\mathrm{ABC}$, and a low score of 77 (at 6\%ile rank) for conceptual domain, which was 11 points above his ABC. Only for practical domain that CT obtained a low average score of 89 (at 23\%ile rank), which was 23 points far above his ABC (see Table 9). His scores for the three domains in the adaptive behavior did not match with the reported findings of these studies. In fact, his very low adaptive behavior composite was only 8 points behind his borderline PIQ of 74, and hence, closer to his intellectual ability than the other three domains of his adaptive behavior. CT's results suggested that he had a very low independent functioning level to commensurate with his borderline intellectual functioning.

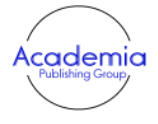

International Journal of Educational Studies Vol. 2, No. 1, pp. 13-35

2019

DOI: 10.53935/2641-533x.v2il.22

Corresponding Author: Sharon Jieren Wong

Email:wjsharon@gmail.com

Funding: This study received no specific

financial support.

Acknowledgement: The authors wish to thank the parents of CT for their kind permission to use and share the assessment results in this paper. Article History:

Received: 5 December 2018

Revised: 31 December 2018

Accepted: 16 January 2019

Published: 13 February 2019

(C) 2019 by the authors; licensee Academic

Publishing Group

Table-9. The ABDS Results

\begin{tabular}{lcccccc}
\hline \multicolumn{1}{c}{ Subscales } & $\begin{array}{c}\text { Raw } \\
\text { Score }\end{array}$ & $\begin{array}{c}\text { Index } \\
\text { Score }\end{array}$ & SEM & $\begin{array}{c}\text { \%ile } \\
\text { Rank }\end{array}$ & Descriptor & $\begin{array}{c}\text { Age } \\
\text { Equiv. }\end{array}$ \\
\hline Conceptual domain & 113 & 77 & 4 & $6 \%$ ile & Low & $6: 00$ \\
Social domain & 70 & 44 & 4 & $<1 \%$ ile & Extremely Low & $2: 06$ \\
Practical domain & 77 & 89 & 4 & $23 \%$ ile & Low Average & $5: 10$ \\
Adaptive Behavior & 210 & 66 & 3 & $1 \%$ ile & Very Low & \\
Composite & & & & & & \\
\hline
\end{tabular}

According to several studies (e.g., Fenton et al., 2003; Perry et al., 2009; Kanne et al., 2011), the adaptive behavior of individuals with both ASD and intellectual disability has been found to commensurate with or greater than, intellectual ability. However, Lee and Park (2007) have found that those with HFAD show a broad gap between IQ and adaptive behavior, with adaptive behavior falling one to two standard deviations 
below the population mean, despite average intelligence. Thus, when compared to typically developing peers matched on intellectual ability, those with HFAD demonstrate significantly lower adaptive behavior scores (Kanne et al., 2011). In CT's case, he had an IQ of 74 - within the range of borderline intellectual functioning - and that put him above those with intellectual disability whose IQ is less than 70. CT's adaptive behavior at 66 was eight points below his IQ and though his adaptive behavior composite was lower than his IQ, the gap was not significantly wide.

Other abnormal or anomalous behaviors also come under this third block of skills and abilities. They include the following assessments that were carried out with CT:

\section{- Gilliam Autism Rating Scale (GARS)}

Chronological Age (at the time of testing): 8:03

The Gilliam Autism Rating Scale (GARS; Gilliam, 1995) is used to identify a child with autism from those with other severe behavioral problems. It is based on the definition of autism adopted by the Autism Society of America (1994). According to Gilliam (2006), "[A]t the time of its publication, the GARS was the only test of its kind normed on children who were known to have autism and was also most statistically reliable and valid standardized test for identifying children with autism" (p. v).

Table-10. The GARS Results

\begin{tabular}{|c|c|c|c|c|}
\hline Subtests & $\begin{array}{l}\text { Raw } \\
\text { Score }\end{array}$ & $\begin{array}{l}\text { Scaled } \\
\text { Score }\end{array}$ & $\begin{array}{l}\text { \%ile } \\
\text { Rank }\end{array}$ & SEM \\
\hline Stereotyped Behavior & 14 & 8 & $25 \%$ ile & 1 \\
\hline Communication & 31 & 14 & $91 \%$ ile & 1 \\
\hline Social Interaction & 27 & 10 & $50 \%$ ile & 1 \\
\hline $\begin{array}{l}\text { Developmental } \\
\text { Disturbance }\end{array}$ & 7 & 10 & $50 \%$ ile & 1 \\
\hline Sum of Scaled Scores & & \begin{tabular}{l}
\multicolumn{1}{c}{42} \\
Standard \\
Score
\end{tabular} & $\begin{array}{l}\text { \%ile } \\
\text { Rank }\end{array}$ & SEM \\
\hline Autism Quotient & & 103 & $58 \%$ ile & 3 \\
\hline
\end{tabular}

According to the GARS results (see Table 10 above), CT displayed obvious symptoms typical of ASD and the most problematic issue of concern was his poor communication (Scaled Score $=14$ at $91 \%$ ile rank).

\section{- Autism Behavior Checklist (ABC)}

Chronological Age (at the time of testing): 8:09

The Autism Behavior Checklist (ABC; Krug, Arick, \& Almond, 2008) is a 57-item questionnaire to be completed by parents or teachers. It constitutes one of the components of the Autism Screening Instrument for Educational Planning- $3^{\text {rd }}$ Edition (ASIEP-3; Krug et al., 2008). The ABC is divided into five subscales: sensory behavior, social relating, body and object use, language and communication skills, and social and adaptive skills. Table 11 shows CT's performance in the ABC administration.

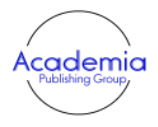

International Journal of Educational Studies Vol. 2, No. 1, pp. 13-35

2019

DOI: $10.53935 / 2641-533 x . v 2 i 1.22$

Corresponding Author: Sharon Jieren Wong

Email:wjsharon@gmail.com

Funding: This study received no specific

financial support.

Acknowledgement: The authors wish to thank the parents of CT for their kind permission to use and share the assessment results in this paper.

Article History:

Received: 5 December 2018

Revised: 31 December 2018

Accepted: 16 January 2019

Published: 13 February 2019

() 2019 by the authors; licensee Academic

Publishing Group

Table-11. The ABC Results

\begin{tabular}{|c|c|c|c|c|c|}
\hline $\begin{array}{c}\text { ABC Profile } \\
\text { No. }\end{array}$ & $\begin{array}{c}\text { Behavioral } \\
\text { Domains } \\
\end{array}$ & $\begin{array}{c}\text { Sub-Total } \\
\text { Scores }\end{array}$ & $\begin{array}{l}\text { Raw } \\
\text { Score }\end{array}$ & $\begin{array}{c}\% \text { (per } \\
\text { domain) }\end{array}$ & $\begin{array}{c}\text { \%age } \\
\text { (overall) }\end{array}$ \\
\hline 1 & Sensory & 26 & 3 & 12 & 2 \\
\hline 2 & Relating (Social) & 38 & 20 & 53 & 13 \\
\hline 3 & $\begin{array}{l}\text { Body \& Object } \\
\text { (Object Relation) }\end{array}$ & 38 & 6 & 16 & 4 \\
\hline 4 & $\begin{array}{l}\text { Language } \\
\text { (Pragmatics) }\end{array}$ & 31 & 27 & 87 & 17 \\
\hline 5 & $\begin{array}{l}\text { Social Self-Help } \\
\text { (Adaptive) }\end{array}$ & 25 & 12 & 48 & 8 \\
\hline $\begin{array}{l}\text { Total Score } \\
\text { Probability }\end{array}$ & Autistic Behavior & $\begin{array}{c}158 \\
\text { Range }\end{array}$ & $\begin{array}{c}68 \\
\text { Mode }\end{array}$ & $\begin{array}{l}43 \\
\text { ely autistic }\end{array}$ & -- \\
\hline
\end{tabular}




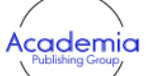

International Journal of Educational Studies Vol. 2, No. 1, pp. 13-35

2019

DOI: $10.53935 / 2641-533 x, v 2 i 1.22$

Corresponding Author: Sharon Jieren Wong

Email:wisharon@gmail.com

Funding: This study received no specific

financial support.

Acknowledgement: The authors wish to thank the parents of CT for their kind permission to use and share the assessment results in this paper. Article History

Received: 5 December 2018

Revised: 31 December 2018

Accepted: 16 January 2019

Published: 13 February 2019

(C) 2019 by the authors; licensee Academic

Publishing Group
According to the $\mathrm{ABC}$ range of scores, any raw score below 47 is very unlikely autistic or to be taken as non-autistic. Scores ranging from 47 to 53 are in the category of conditionally probable autistic, while scores above 54 are in the category of moderately autistic.

In CT's case, with a total raw score of 68 , he was identified as moderately autistic. In terms of the five domains, his biggest challenge was found in Language (Pragmatics) with the highest percentage for that domain and highest percentage among the five domains. Pragmatics concerns with the appropriate use of language within a given social context (or other social contexts). It also concerns with the way CT produces and comprehends meanings through language. In CT's case, the child demonstrated three pragmatic problems: Firstly, he showed a significant difficulty in (i) understanding and (ii) using verbal language, and also (iii) significant problems during social interactions. These three issues of pragmatic concern are typical of the condition known as hyperlexia (Center for Speech and Language Disorders, 2009). "Although hyperlexia may be the key symptom in describing the learning difference in a child, it is not a stand-alone diagnosis. Rather, it exists on a continuum with other disorders, such as autism spectrum disorders, language disorders and nonverbal learning disabilities" (Center for Speech and Language Disorders, 2009, para.2).

\section{- Extreme Demand Avoidance Questionnaire (EDA-Q)}

Chronological Age (at the time of testing): 8:09

Although the Extreme Demand Avoidance Questionnaire (EDA-Q; O'Nions et al., 2014) measures traits of extreme or pathological demand avoidance (PDA for short), it is not a diagnostic test. It is often applied consistently for research purposes.

According to O'Nions et al. (2014), in their study of parent-reported behaviors in children and adolescents, for those aged 5 to 11, a score of 50 and above, and for those aged 12 to 17, a score of 45 and above, indicated an elevated risk of parents reporting that the child had been clinically identified as having a profile resembling PDA. However, a lower score would not necessarily preclude PDA from being a factor, especially when such behavioral traits are subtle, such as where aggression may be less of a factor or where avoidant traits may be less overt). PDA is dimensional. That means it impacts different people in different ways and in different environments. Hence, the EDA-Q score should be interpreted dimensionally rather than as a formal cut- off point.

The 26-item questionnaire is scored on 4-point Likert scale: $0=$ not true, $1=$ somewhat true, $2=$ mostly true, and $3=$ very true. Only two items \#14 and \#20 in the questionnaire are reversely scored. The total possible score for all 26 items is 78 .

In CT's case, with a score 31 out of total score of 78, and his age fell within the range of those aged 5-11, the result suggested that he was not at risk of having PDA.

\subsection{Block IV of Social-Emotional Skills and Abilities}

No formal assessment was administered under this fourth building block of social-emotional skills and abilities. However, in the Block II of sensory behavioral skills and abilities, the SP-2C results indicated that with a sensor-bystander sensory profile, CT also showed sensory over-responsivity for his social-emotional behavioral responses associated with sensory processing. In the overall summary of his sensory behavior profile, CT displayed a la belle indifference attitude in almost all situations. This la belle indifference indicates the child's inappropriately complacent attitude towards his current behavioral condition in any context (e.g., in the park or at home) and physical symptoms, which are often observed in patients with conversion disorder and hysteria (Stone et al., 2006).

\subsection{Block V of Academic Skills and Abilities}

This block of skills and abilities is related to academic or educational attainments. As mentioned earlier, this block includes higher levels of cognition, involving word knowledge (i.e., active and passive vocabularies), general knowledge, ability to count and perform operational functions involving numbers and ability to carry out activities using both verbal and nonverbal reasoning skills.

Under this Block IV, several literacy-based tests were carried out with CT. They include the following tests: (i) Carver Word Recognition Test (CWRT); (ii) Schonell Reading Test-Revised (SRT-R); (iii) Schonell Graded Word Spelling Test (SGWST); (iv) Aston Vocabulary Scale (ASV); and (v) Neale Analysis of Reading Ability-Revised (British Edition) (NARA-R-BE). Another standardized test - Renfrew Word Finding 
Vocabulary Test (RWFVT) - was administered a few years ago but the record was not available at the time of writing this paper.

The results of these tests are briefly discussed below.

- Carver Word Recognition Test (CWRT)

Chronological Age (at the time of testing): 8:09

Carver Word Recognition Test (CWRT; Carver, 1970) is an attainment diagnostic test that can be administered individually or in a group for children between 4:06 and 8:06. Its score provides word recognition age as well as a child's developmental stage in word recognition.

Table-12. The CWRT Results

\begin{tabular}{lc}
\hline & Score \\
\hline Raw Score & 50 \\
Word Recognition Age & $>8: 06$ \\
Word Recognition Stage & 10 \\
Quotient & Cannot be determined \\
Descriptor & Advanced \\
\hline
\end{tabular}

Table 12 above shows CT's word recognition development at Stage 10 at that time of assessment. The result indicates that the child had attained "[A] thorough knowledge of the double initial consonants now established; probably all simple single letter endings known. Simpler endings such as -ing established; beginning to conquer $s t, s l, s n, s m, s p$; insight into $t h, t w$ (initially); manipulating groups such as or, ow, oy, but complex initial groups yet to be conquered ( $s p r, s t r, t h r)$, and difficult endings such as $t h$, $s h$; recognition of difficult groups such as ir, er, ur, developing" (Carver, 1970, p.6).

CT's performance in word recognition was ahead of his age of 8 years 9 months at the time when the assessment was done. As the ceiling cut-off age for the CWRT was 8 years 6 months, CT's ability to recognize words should have exceeded it. In that sense, the CWRT result could not give the equivalent age for his performance in word recognition.

\section{- Schonell Reading Test-Revised (SRT-R)}

Chronological Age (at the time of testing): 8:09

The Schonell Reading Test-Revised (SRT-R; Shearer, 1972) is one of the seven tests that form the original Schonell Reading Tests (Schonell \& Schonell, 1950, 1952), which measure reading attainment in order to identify the aspects of failure in some of the mechanics of reading.

According to Newton and Thomson (1978), the SRT-R is included as one of the several standardized subtests in the Aston Index-Revised; the others being the Goodenough Draw-a-Man Test, the Aston Vocabulary Scale and the Schonell Graded Spelling Test. The SRT-R, which is one of the most widely used in Singapore and the UK, is based on a 'look-and-say' (or visual-oral decoding) approach and it provides wordreading levels from ages five to 15 years.

International Journal of

2019

DOI: $10.53935 / 2641-533 x . v 2 i 1.22$

Corresponding Author: Sharon Jieren Won

Email:wjsharon@gmail.com

Funding: This study received no specific

financial support.

Acknowledgement: The authors wish to thank the parents of CT for their kind permission to use and share the assessment results in this paper.

Article History:

Received: 5 December 2018

Revised: 31 December 2018

Accepted: 16 January 2019

Published: 13 February 2019

(C) 2019 by the authors; licensee Academic

Publishing Group

| 26
Table-13. The SRT-R Results

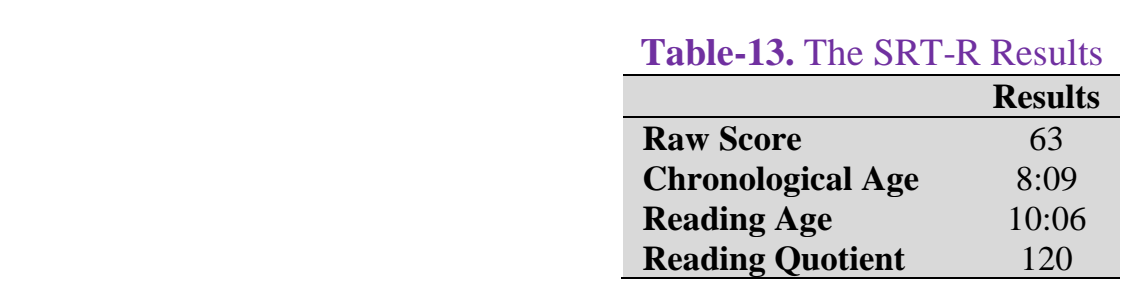

CT's results (see Table 13 above) obtained in the SRT-R show that the child's reading age of 10 years 6 months was 21 months ahead of his chronological age at the time of assessment. His reading quotient of 120 puts him in the superior range. In other words, CT was assessed to be a superior decoder of words by sight.

\section{- Schonell Graded Word Spelling Test (SGWST)}

Chronological Age (at the time of testing): 8:09 
The Schonell Graded Word Spelling Test (SGWST; Schonell, 1955) requires a child to spell a number of words that have been graded for difficulty to obtain a raw score that can be used to calculate his/her spelling age using the following formula: Spelling Age $=[($ Number of Words correctly spelt $\div 10)+5]$.

\begin{tabular}{lc} 
Table-14. The SGWST Results \\
\hline & Results \\
\hline Raw Score & 58 \\
Chronological Age & $8: 09$ \\
Spelling Age & $10: 10$ \\
Spelling Quotient & 124 \\
\hline
\end{tabular}

CT's performance in SGWST (see Table 14 above) show his spelling age of 10 years 10 months was 25 months ahead of his chronological age of 8 years 9 months. In other words, the spelling quotient of 124 puts CT's spelling performance in the superior range. CT was a superior speller besides being a superior decoder in his reading as shown in his SRT-R results mentioned above. This means that since young, between three and five years of age, CT possessed an uncanny ability to segment words into their constituent letter sounds to decipher words for both reading and spelling without being formally taught at all.

\section{- Aston Vocabulary Scale (AVS)}

Chronological Age (at the time of testing): 8:09

Aston Vocabulary Scale is one of the several subtests found in the Aston Index-Revised (Newton and Thomson (1978). It measures a child's ability to express his understanding of the nature or use of the words. This is word knowledge or vocabulary.

Before a child is able to use a word correctly and fully, he has to know quite a bit about it, especially its meaning and usage. An important distinction exists, therefore, concerning the words that the child has in mind. To capture this distinction, Benjamin and Crow (2012) use the terms receptive and productive to differentiate the two types of word knowledge: The former refers to an individual in receptive control of the words that he understands when he hears them or read them; and the latter refers to the individual in productive control of the words that he uses to express himself, in speech or in writing. A child's receptive vocabulary is often much larger than his productive vocabulary. In fact, almost every literate adult has a much larger receptive word knowledge.

When CT was five years old, his Vocabulary Acquisition Index score based on the WPPSI-IV results was in the borderline range (70-79). According to CT's psychological report, although both his receptive and expressive vocabulary skills were poor as compared with his peers of the same age, CT was able to present with adequate expressive vocabulary skills but very poor receptive vocabulary skills.

By eight years, CT knew and recognized a lot more words. However, he was still unable to express them meaningfully in speech or in writing. His receptive vocabulary (based on an earlier administration of the Renfrew Word Finding Vocabulary Test or RWFVT for short; Renfrew, 1998) remained a big challenge and was weaker than his productive vocabulary. The RWFVT assessed CT's expressive vocabulary (compared, for instance, with the Peabody Picture Vocabulary Test, which is a test of receptive vocabulary). The RWFVT assesses the extent to which pictures of objects, arranged in order of difficulty, can be named correctly. Most of the objects illustrated have no alternative names, so the responses of children can be quickly measured. The assessment contains 50 line-drawn pictures and is suitable for children aged 3-9 years. CT was noted to be quick at naming the objects he saw except for some unfamiliar pictures such as antenna and spire.

However, CT scored below an age equivalent of less than 5 years (or vocabulary quotient <57) on the AVS. This result indicated that CT had semantic (meaning) problems, too, at the word level. The semantic knowledge consists of the following two main areas:

1. Logical semantic knowledge that is concerned with matters, such as sense and reference, and presupposition and implication; and

2. Lexical semantic knowledge that is concerned with the analysis of word meanings and relations between them.

With this aspect of language impaired, CT encountered a huge challenge in understanding the nature and use of words in both reading comprehension and written composition. 
- Neale Analysis of Reading Ability-Revised (British Edition) (NARA-R-BE)

Chronological Age (at the time of testing): 8:10

The Neale Analysis of Reading Ability-Revised (British Edition) (NARA-R-BE; Neale, Christophers, \& Whetton, 1989) is a comprehensive assessment of reading ability aimed for use with pupils aged 6 to 12 years. The test is designed to assess oral reading ability in terms of reading rate, accuracy and comprehension, as well as to be used as a diagnostic assessment tool.

Table 15 provides a summary of CT's performance in the NARA-R-BE for the three measures in his reading ability:

1. Reading rate (also known as reading speed);

2. Reading accuracy (decoding ability); and

3. Reading comprehension.

Table-15. The NARA-R-BE Results

\begin{tabular}{lccc}
\hline & Reading Rate & Reading Accuracy & $\begin{array}{c}\text { Reading } \\
\text { Comprehension }\end{array}$ \\
\hline Raw Scores & 93 & 73 & 12 \\
Reading Age & $12: 10+$ & $10: 08$ & $7: 04$ \\
Reading Quotient & $>145$ & 120 & 83 \\
Descriptor & Extremely Superior & Superior & Low Average \\
95\% Confidence Interval & $12: 02-20: 00$ & $12: 03-17: 02$ & $6: 08-9: 02$ \\
Percentile Rank & $99+\%$ ile & $99+\%$ ile & $21 \%$ ile \\
Stanine & 9 & 9 & 3 \\
\hline
\end{tabular}

The results show that $\mathrm{CT}$ at the chronological age of 8 years 10 months was a fast and accurate decoder at the age equivalent of more than 12 years 10 months (or an extremely superior reading quotient of >145 at $99+\%$ ile rank) for his reading rate and 10 years 8 months (or a superior reading quotient of 120 at $99+\%$ ile rank) for his reading accuracy, respectively.

However, CT's performance in reading comprehension was poor given his age equivalent of 7 years 4 months (or a low average reading quotient of 83 at 21\%ile rank) in the range between 6 years 8 months and 9 years 2 months. That means his reading comprehension age was 40 months lagging behind his reading accuracy age at that time of assessment. In other words, CT displayed an advanced word-recognition skill despite his pronounced cognitive, social and linguistic handicaps (Nation, 1999). Such an unusual performance spells an atypical behavior of an individual with hyperlexia.

Out of the cumulative number of 491 words based on six reading passages provided in the assessment, CT made only 29 errors. Table 16 shows a summary of CT's error counts recorded during the NARA-R-BE administration. In other words, the errors that CT had committed was an insignificant $6 \%$. Of this small percentage of error types, $48 \%$ of CT's reading errors was in mispronunciation, $38 \%$ in substitution errors and $14 \%$ in omission errors. That means CT was indeed a superior decoder of words given his superior reading quotient of 120 for his reading accuracy.

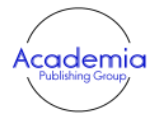

International Journal of Educational Studies Vol. 2, No. 1, pp. 13-35

2019

DOI: $10.53935 / 2641-533 x . v 2 i 1.22$

Corresponding Author: Sharon Jieren Wong

Email:wjsharon@gmail.com

Funding: This study received no specific

financial support.

Acnowledgement: The authors wish to thank the parents of CT for their kind permission to use and share the assessment results in this paper.

Article History:

Received: 5 December 2018

Revised: 31 December 2018

Accepted: 16 January 2019

Published: 13 February 2019

(C) 2019 by the authors; licensee Academic

Publishing Group

Table-16. Error Types made by CT in his Reading

\begin{tabular}{cccccccc}
\hline Error Types & $\begin{array}{c}\text { Mis- } \\
\text { pronunciation }\end{array}$ & Substitution & Refusal & Addition & Omission & Reversal & Total \\
\hline $\begin{array}{c}\text { Total Count } \\
\text { \% of Total }\end{array}$ & 14 & 11 & 0 & 0 & 4 & 0 & 29 \\
Count & 48 & 38 & 0 & 0 & 14 & 0 & 100 \\
\hline
\end{tabular}

CT was able to answer correctly 12 out of 44 comprehension questions based on the six reading passages. Those questions that CT answered correctly were mainly at literal comprehension level. He did very poorly for questions related to inferential comprehension. In other words, he displayed a serious reading comprehension deficit. With an age equivalent of 7 years 4 months for his reading comprehension, CT's reading comprehension quotient was 83 (low average). 


\section{Discussion of Findings}

CT had a normal birth/medical history delivered via forceps at $39^{\text {th }}$ gestation week. He passed his Apgar scores and neonatal screening. There was no indication of at-risk factors for any developmental delay at infancy (see $\mathrm{EDM}^{4}$, diagnostic code EI 3.00, p.424-425).

When CT turned three years of age, his parents noticed he was not developing like any other children of his age group. While every other aspects of his developmental milestones were within normal limits, his speech-language development was especially delayed and he had difficulties in communicating meaningfully or socializing appropriately with other children as well as his parents. Speech-language development is considered to be an important indicator of a child's overall development and cognitive or intellectual ability (Schuster, 2000) and is related to future school success (Bishop \& Clarkson, 2003; Schuster et al., 2002). Hence, CT was suspected to have developmental delays (EDM: PS-DD 1.00) in the following domains: adaptive behavior skills (EDM: PS-DD 1:01), cognitive abilities (EDM: PS-DD 1.02), communication (EDM: PS-DD 1.03) and social-emotional skills (EDM: PS-DD 1.05).

Moreover, CT was later assessed by a psychologist at a public hospital to have autistic disorder (based on ADOS-2 Module 1 results) (EDM: AU 2.00).

At five years old, although not explicitly told, CT was identified to have intellectual disability (ID) (based on WPPSI-IV results) with FSIQ $<69$ and his verbal comprehension and processing speed skills were in the extremely low range $\left(\mathrm{SS}^{5}<69\right)$. Also known as intellectual developmental disorder (IDD) (EDM: No diagnostic code available; DSM-5 diagnostic code: 317), the level of severity was not known since no quantitative data had been provided. He was also assessed to have adaptive behavior skill deficits (based on VABS-2 results where CT's adaptive behavior composite was within the moderately low range).

When CT was eight years old, he was assessed on another IQ test, i.e., the Pictorial Test of Intelligence$2^{\text {nd }}$ Edition, which does not depend heavily on the use of verbal (spoken and written) language in the assessment (DeThorne \& Barbara, 2004). He was found to have a borderline intellectual functioning capacity with a Pictorial IQ of 74 (based on the PTI-2 results). He was re-classified as being high functioning (since his IQ was above the cut-off SS=71) (DSM-5 diagnostic V-code: 62.89) with moderate autistic disorder (based on the GARS and ABC results) (EDM: AU 4.00).

CT continued to display adaptive behavior skill deficits (based on the ABDS results). In other words, CT displayed social incompetence due to developmental delay including intellectual disability. The term social competence refers to "the ability to demonstrate personal independence and social responsibility in everyday contexts" (Saulnier \& Klaiman, 2018, p.4-5) or "may be defined as a functional composite of human traits which subserves social usefulness as reflected in self-sufficiency and in service of others" (Doll, 1953, p.2).

CT's major issue of concern in his adaptive behavior was his poor communication and/or social interaction (based on the ABDS and GARS results) due to his severe comprehension deficit caused by his impaired semantic-pragmatic knowledge and skills (based on the AVS and ABC results), which also affected how CT was producing and comprehending meanings through language. It seems that CT might have semantic-pragmatic disorder ${ }^{6}$ which is believed to be closely related to ASD (Bishop, 1989). However, "it is now generally agreed that there is little correlation between semantic and pragmatic behaviors as such: they can exist together but not necessarily" (Gardner, 2011, para.4).

CT's pragmatic problems included a significant difficulty in understanding and using verbal language, and significant problems in social interactions. Today, this condition is known as pragmatic language impairment (PLI) or social (pragmatic) communication disorder (SCD) (the official term used in the DSM-5), which was previously known as semantic-pragmatic disorder (SPD). It is an impairment in understanding pragmatic aspects of language. PLI or SCD is now a diagnosis in the DSM-5. The diagnosis SCD (DSM-5 diagnostic code: 315.39 ) can only be given if the symptoms "are not attributable to another medical or neurological condition or to low abilities in the domains of word structure and grammar, and are not better explained by ASD (DSM-5 diagnostic code: 299.00), IDD (DSM-5 diagnostic code: 317), global developmental delay, or

\footnotetext{
${ }^{4}$ EDM stands for Educator's Diagnostic Manual of Disabilities and Disorders (Pierangelo \& Giuliani, 2007) from where the diagnostic codes will be quoted unless otherwise stated.

${ }^{5}$ SS stands for Standard Score.

${ }^{6}$ The semantic-pragmatic disorder is no longer used today. In the fifth edition of DSM, the term pragmatic language impairment (PLI) or social (pragmatic) communication disorder (SCD) is used instead.
} 
another mental disorder" (Indiana Resource Center for Autism, 2019, para.9; also see DSM-5, APA 2003; Criterion D, diagnostic code 315.39).

Children with SCD (or PLI) have special challenges with the semantic aspect (vocabulary) of language (i.e., the meaning of what is being spoken or written) and the pragmatics of language (using language appropriately in social situations). In CT's case, he had poor semantic knowledge (more so with his receptive vocabulary than his expressive vocabulary) with a vocabulary quotient $<57$ (as shown in the AVS results). Hence, he faced a huge challenge in understanding the nature and use of words in both reading comprehension and written composition. It is not surprising that children with ASD, like CT, will experience difficulty in understanding the meaning of what is being spoken to them due to different ways of responding to social situations. CT's semantic knowledge was impaired in terms of poor logical semantic knowledge (e.g., sense and reference, and presupposition and implication) and poor lexical semantic knowledge (i.e., analysis of word meanings and relations between them).

CT's sensor-bystander sensory profile showed that he had sensory over-responsivity for his socialemotional behavioral responses associated with sensory processing (as shown in the SP-2C results). This condition is also known as sensory integration disorder (SID) (EDM: LD 10.00) and is also known as sensory processing disorder (SPD). There are three main types of SID/SPD: (i) sensory modulation disorder, in which an individual either over-responds or under-responds to sensory information and s/he may appear uncooperative, stubborn and easily frustrated; (ii) sensory-based motor disorder (or motor-based sensory disorder), in which an individual has motor-planning problems, and this condition may be linked to developmental coordination disorder or dyspraxia; and (iii) sensory discrimination disorder, in which an individual appears unfocused and disorganized (Miller et al., 2009) and his/her executive functioning skills will also be problematic. Though SID/SPD is not officially recognized and listed in the DSM-5 and ICD-10, it is listed in the Diagnostic Classification of Mental Health and Developmental Disorders of Infancy and Early Childhood (DC:0-5 ${ }^{\mathrm{TM}}$; Zero-to-Three, 2016).

Rather than being a child with challenging or aggressive behavior due to sensory issues of concern, CT displayed more of a la belle indifference in almost all situations. This la belle indifference indicated the child's inappropriate complacent attitude towards his current behavioral condition in any context. Although CT also showed a more-than-other avoider sensory profile in the SP-2C results, he did not have any serious traits of extreme/pathological demand avoidance behavior (as shown in the EDA-Q results). However, CT showed a poor sense of bodily awareness (as shown in the SP-2C results) which is indicative of proprioceptive perceptual sensory integration disorder (EDM diagnostic code: LD 10.02), and alexithymia was also highly suspected. With interventions targeting at alexithymia, CT's emotional coherence could be increased so that, in turn, it could improve his socio-emotional communication.

Moreover, with extremely superior reading rate $(\mathrm{SS}>145)$ and superior reading accuracy $(\mathrm{SS}=120)$ (as shown in the NARA-R-BE results) and superior spelling ( $\mathrm{SS}=124)$ (as shown in the SGWST results), CT displayed advanced word-recognition skills, committing only $6 \%$ of reading errors. However, he had a low average performance in reading comprehension ( $\mathrm{SS}=83$ ) (as shown in the NARA-R-BE results) and only able to answer correctly $27 \%$ of all 44 comprehension questions (mainly at the level of literal comprehension). A wide discrepancy between his reading ability and his reading comprehension performance was noted. With rapid processing speed and superior decoding, CT's reading performance was nothing more than a mechanical process of barking at print without real comprehension. With his performance in reading, word recognition (as shown in the CWRT results) and spelling way above than his performance in reading comprehension, CT was obviously struggling with the autistic condition known as hyperlexia (EDM diagnostic code: AU 5.00).

Finally, CT's condition can be summarized as follows: It began with no-risk development at infancy, but over a period of time, it was observed that CT displayed at-risk factors in developmental delay which was later diagnosed with moderate autistic disorder with borderline intellectual functioning and poor adaptive behaviour skills but displays an intense fascination with both letters (lexicophilia) and numbers (numerophilia) and an advanced word-recognition or reading ability but poor semantic understanding of words (hyperlexia). Despite CT's fantastic feats in word recognition/reading and spelling performance at the time of assessment, the child displayed serious problem in social interaction and communication (not to be confused with the condition of SCD) due to his poor comprehension of the nature or use of the words. This condition of hyperlexia has been regarded as a type of autism (Pierangelo \& Guiliani, 2007) and given a diagnostic code AU 5.00 in the Educator's Diagnostic Manual (EDM; Pierangelo \& Guiliani, 2007).

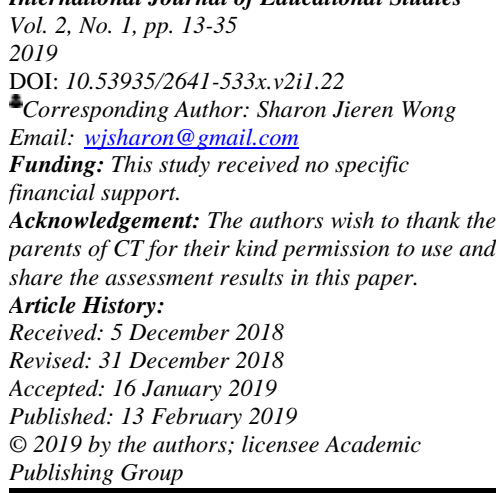


Figure 2 below shows a nosographical representation of CT's syndromic complex condition of autistic disorder. The term syndromic is used here to denote that the traits of CT's autistic disorder are also associated with other psycho-medical and behavioural signs and symptoms of other disorders and conditions, which include in the following key:

1. Borderline Intellectual Functioning (IQ=74) (DSM-5 diagnostic V-code: 62.89)

2. Moderate Autistic Disorder (High-functioning; IQ >71) (DSM-5 diagnostic code: 299.00) (EDM diagnostic code: AU 4.00)

3. Sensory Processing Disorder (EDM diagnostic code: LD 10.00) or Sensory Integration Disorder (consult the DC:0-5 ${ }^{\mathrm{TM}}$ for its diagnostic code)

4. Semantic-Pragmatic Disorder (old term); Pragmatic Language Impairment or Social (Pragmatic) Communication Disorder (DSM-5 diagnostic code: 315.39 )

5. Hyperlexia (EDM diagnostic code: AU 5.00) $\leftarrow$ Lexicophilia (no official diagnostic code) and/or Numerophilia (no official diagnostic code); poor word knowledge, especially with deficit in receptive vocabulary $>$ deficit in expressive vocabulary

6. Adaptive Behavior Skill Deficits (no official diagnostic code)

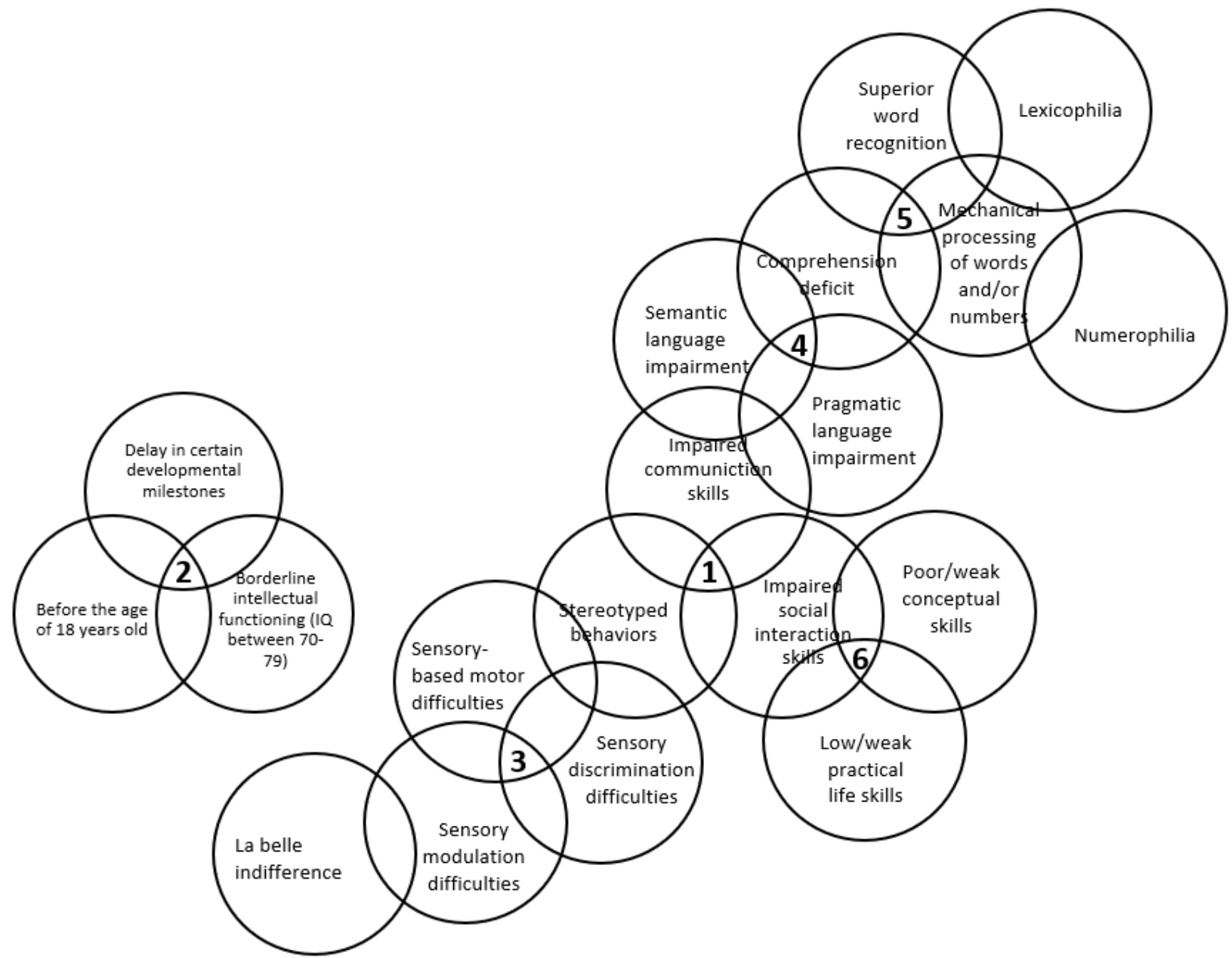

Figure-2. A Syndromic Complex Condition of Autistic Disorder

Vol. 2, No. 1, pp. 13-35

2019

DOI: $10.53935 / 2641-533 x . v 2 i 1.22$

Corresponding Author: Sharon Jieren Wong

Email: wjsharon@gmail.com

Funding: This study received no specific

financial support.

Acknowledgement: The authors wish to thank the parents of CT for their kind permission to use and share the assessment results in this paper.

Article History:

Received: 5 December 2018

Revised: 31 December 2018

Accepted: 16 January 2019

Published: 13 February 2019

(C) 2019 by the authors; licensee Academic

Publishing Group

The nosographical representation of CT's syndromic complex condition of autistic disorder shows the pleiotropy ("one-to-many") of the autistic condition as presented in Figure 3 below: 


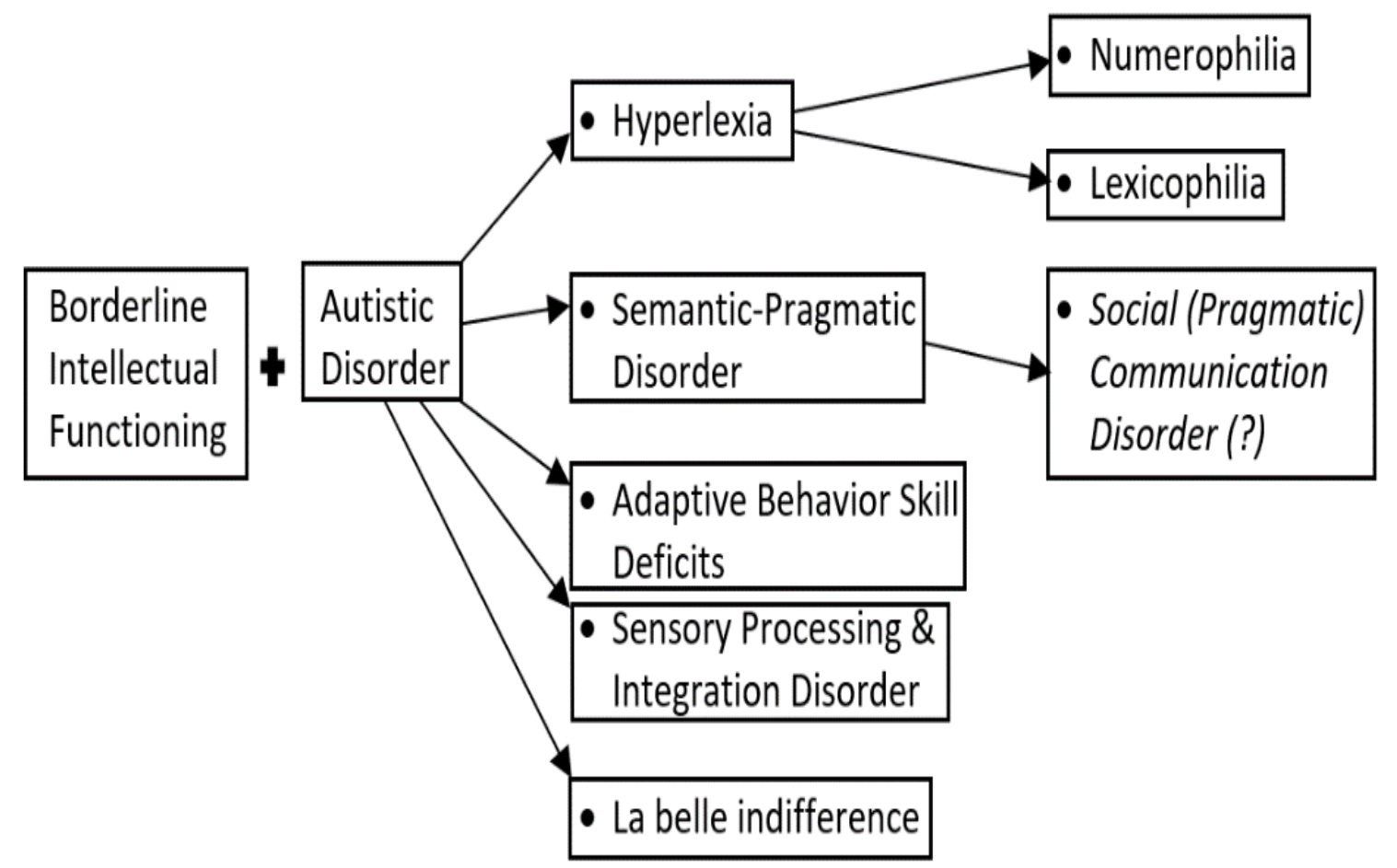

Figure-3. Pleiotropy of Autistic Disorder

Given the detailed diagnostic evaluation and a better understanding of CT's syndromic complex condition of autistic disorder, it provides as accurate as possible an ASD diagnosis with a functional level (i.e., adaptive behavior skills), at least in theory, so that the educational therapists working with him would be able to draw a clear picture of his abilities and needs (Rudy, 2018).

This, in turn, could enable the educational therapists and other allied professionals to design an appropriate multi-disciplinary intervention program according to one of the three different severity levels (where Level 1 requires support; Level 2 requires substantial support; and Level 3 requires very substantial support) to help CT cope with his learning and behavioral issues of concern.

\section{References}

American Psychiatric Association (2000). Diagnostic and Statistical Manual of Mental Disorders-4 ${ }^{\text {th }}$ Edition-Text Revision (DSM-IV-TR). Washington, DC: The Author.

American Psychiatric Association (2013). Diagnostic and Statistical Manual of Mental Disorders-5 ${ }^{\text {th }}$ Ed. (DSM-5). Washington, DC: The Author.

Autism Society of America (1994). Definition of autism. The Advocate: Newsletter of the Autism Society of America, 26(2): 3 .

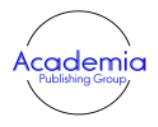

International Journal of Educational Studies Vol. 2, No. 1, pp. 13-35

2019

DOI: $10.53935 / 2641-533 x . v 2 i 1.22$

Corresponding Author: Sharon Jieren Wong

Email:wwsharon@gmail.com

Funding: This study received no specific

financial support.

awledgement: The authors wish to thank the parents of CT for their kind permission to use and share the assessment results in this paper. Article History:

Received: 5 December 2018

Revised: 31 December 2018

Accepted: 16 January 2019

Published: 13 February 2019

(C) 2019 by the authors; licensee Academic

Publishing Group

Bainbridge, C. (2018). Overview of hyperlexia in children. Available from: https://www.verywellfamily.com/hyperlexiadefinition-and-diagnosis-1449188?print.

Benjamin, A., \& Crow, J.T. (2012). Vocabulary at the core: Teaching the common core standards. New York: Eye on Education, Inc.

Bishop, D.V.M. (1989). Autism, Asperger's syndrome and semantic-pragmatic disorder: Where are the boundaries? British Journal of Disorders of Communication, 24: 107-121.

Bishop, D.V.M., \& Clarkson, B. (2003). Written language as a window into residual language deficits: A study of children with persistent and residual speech and language impairments. Cortex, 39: 215-237.

Bleuler, E. (1911). Dementia Praecox oder Gruppe der Schizophrenien. Leipzig, Germany: Deuticke.

Camulli, J.E., \& Goh, L.A.L. (2018). Re-conceptualizing autistic savantism as a spectrum syndromic disorder: A sequel to the case study of a young adult savant artist. European Journal of Special Education Research, 3(4): 185-203.

Carver, C. (1970). Word Recognition Test. Manchester, UK: Hodder and Stoughton.

Catts, H.W., Fey, M.E., Tomblin, J.B., \& Zhang, X. (2002). A longitudinal investigation of reading outcomes in children with language impairments. Journal of Speech Language and Hearing Research, 45: 1142-1157. 
Center for Speech and Language Disorders (2009). Helping individuals reach their full potential: Hyperlexia. Available from: https://csld.org/hyperlexia.

Chia, K.H. (2008). Educating the whole child in a child with special needs: What we know and understand and what we can do. ASCD Review, 14: 25-31.

Chia, K.H. (2012). Autism enigma: The need to include savant and crypto-savant in the current definition. Academic Research International, 2(2): 234-240.

Chua, C.K., \& Chia, K.H. (2017). Branching out from autistic savantism: Identifying and defining autistic cryptosavantism in individuals with non-verbal/verbal low-functioning autism. European Journal of Special Education Research., 2(4): 16-34.

Costa, A., Steffgen, G., \& Samson, A.C. (2017). Expressive incoherence and alexithymia in autism spectrum disorder. Journal of Autism and Developmental Disorders, 47(3): 1-14.

DeThorne, L.S., \& Barbara A. Schaefer, B.A. (2004). A guide to child nonverbal IQ measures. American Journal of Speech-Language Pathology, 13(4): 275-290.

DB.net (2018). Difference between ability and skill. Available from: http://www.differentbetween.net/language/difference-between-ability-and-skill/\#ixx5WS3m4H.

Di Lavore, P., Lord, C., \& Rutter, M. (1995). The pre-linguistic Autism Diagnostic Observation Schedule. Journal of Autism and Developmental Disorders, 25: 355-379.

Doll, E.A. (1953). The measurement of social competence: A manual for the Vineland Social Maturity Scale. Minneapolis, MN: Educational Test Bureau.

Dunn, W. (2014). Sensory Profile-2 ${ }^{\text {nd }}$ Edition (SP-2). Bloomington, MN: PsychCorp.

Dvir, Y., \& Frazier, J.A. (2011). Autism and schizophrenia. Psychiatric Times, May 16. Available from: http://www.psychiatrictimes.com/autism/autism-and-schizophrenia.

Eaves, R.C., \& Williams, T.O. (2005). Pictorial Test of Intelligence- $2^{\text {nd }}$ Edition (PTI-2). Austin, TX: Pro-Ed.

Ellis, S.E., Panitch, R., West, A.B., \& Arking, D.E. (2016). Transcriptome analysis of cortical tissue reveals shared sets of downregulated genes in autism and schizophrenia. Translational Psychiatry, 6(5): e817.

Fenton, G., D'Ardia, C., Valenta, D., Vecchio, I.D.V., Fabrizi, A., Bernabei, P., (2003). Vineland adaptive behavior profiles in children with autism and moderate to severe developmental delay. Autism, 7(3): 269-287.

Fiksinski, A.M., Breetvelt, E.J., Duijff, S.N., Bassett, A.S., Kahn, R.S., \& Vorstman, J.A.S. (2017), Autism spectrum and psychosis risk in the 22q11.2 deletion syndrome: Findings from a prospective longitudinal study. Schizophrenia Research, 188: 59-62.

Gardner, H. (2011, 26 September). Semantic pragmatic disorder: The reality behind the label. Available from: https://senmagazine.co.uk/articles/articles/senarticles/semantic-pragmatic-disorder-the-reality-behind-the-label.

Gilliam, J.E. (1995). Gilliam Autism Rating Scale (GARS). Austin, TX: Pro-Ed.

Gilliam, J.E. (2006). Gilliam Autism Rating Scale-2 ${ }^{\text {nd }}$ Edition (GARS-2). Austin, TX: Pro-Ed.

Heber, R.A. (1961). A manual on terminology and classification in mental retardation: Monograph supplement to the American Journal of Mental Deficiency ( $2^{\text {nd }}$ Ed.). Springfield, IL: American Association on Mental Deficiency.

Indiana Resource Center for Autism (2019). Diagnostic criteria for social (pragmatic) communication disorder. Available from: https://www.iidc.indiana.edu/pages/diagnostic-criteria-for-social-pragmatic-communication-disorder1.

Iossifov, I., Ronemus, M., Levy, D., Wang, Z., Hakker, I., Rosenbaum, J., Yamrom, B., Lee, Y.H., Narzisi, G., \& Leotta A. (2012). De novo gene disruptions in children on the autistic spectrum. Neuron, 74: 285-299.

Julita (2011). Difference between ability and skill. DifferenceBetween.net. Available from: http://www.differencebetween.net/language/difference-between-ability-and-skill/.

Kanne, S.M., Gerber, A.J., Quirmbach, L.M., Sparrow, S.S., Cicchetti, D.V., \& Saulnier, C.A. (2011). The role of adaptive behaviour in autism spectrum disorders: Implications for functional outcome. Journal of Autism and Developmental Disorders, 41(8): 1007-1018.

Klin, A., Saulnier, C.A., Sparrow, S.S., Cicchetti, D.V., Volkmar, F.R., \& Lord, F.R. (2007). Social and communication abilities and disabilities in higher functioning individuals with autism spectrum disorders: The Vineland and the ADOS. Journal of Autism and Developmental Disorders, 37(4): 748-759.

International Journal of Educational Studies Vol. 2, No. 1, pp. 13-35

2019

DOI: $10.53935 / 2641-533 x$ v2il.22

Corresponding Author: Sharon Jieren Wong

Email:wjsharon@gmail.com

Funding: This study received no specific

financial support.

nowledgement: The authors wish to thank the parents of CT for their kind permission to use and share the assessment results in this paper. Article History.

Received: 5 December 2018

Revised: 31 December 2018

Accepted: 16 January 2019

Published: 13 February 2019

(C) 2019 by the authors; licensee Academic

Publishing Group

Kraepelin, E. (1887a). The directions of psychiatric research: lecture, held at the acquisition of the Magisterium of the Imperial University Dorpat. Leipzig, Germany: bird.

Kraepelin, E. (1887b). Psychiatrie: Ein kurzes Lehrbuch für Studirende und Aerzte. 2nd Edn., Leipzig, Germany: Abel.

Krug, D.A., Arick, J.R., \& Almond, P.J. (2008). Autism Behavior Checklist (ABC). Austin, TX: Pro-Ed.

Krug, D.A., Arick, J.R., \& Almond, P.J. (2008). Autism Screening Instrument for Educational Planning-3 ${ }^{\text {rd }}$ Edition (ASIEP-3). Austin, TX: Pro-Ed.

Lai, M-C., Lombardo, M.V., Chakrabarti, B., \& Baron-Cohen, S. (2013). Subgrouping the autism spectrum: Reflections on DSM-5. PLoS Biology, 11(4): 1-7.

Lee, H.J., \& Park, H.R. (2007). An integrated literature review on the adaptive behavior of individuals with Asperger syndrome. Remedial and Special Education, 28(3): 132-139. 
McKusick, V.A. (1969). On lumpers and splitters, or the nosology of genetic disease. Birth Defects: Original Articles Series, 5(1): 23-32.

Miller, L.J., Nielsen, D.M., Schoen, S.A., \& Barbara A. Brett-Green, B.A. (2009). Perspectives on sensory processing disorder: a call for translational research. Frontiers in Integrative Neuroscience, 3(22): 1-12.

Nation, K. (1999). Reading skills in hyperlexia: A developmental perspective. Psychological Bulletin, 125(3): 338-355.

Neale, M. D., Christophers, U., \& Whetton, C. (1989). Neale Analysis of Reading Ability-Revised (British Edition) (NARA-R-BE). Windsor, UK: NFER-Nelson.

Newton, M.J., \& Thomson, M.E. (1978). The Aston Index: A classroom test for screening and diagnosis of language difficulties (Revised) (AI-R). Wisbech, Cambs, UK: Learning Development Aids.

O’Nions, E., Christie, P., Gould, J., Viding, E., \& Francesca Happé, F. (2014). Development of the 'Extreme Demand Avoidance Questionnaire' (EDA-Q): Preliminary observations on a trait measure for Pathological Demand Avoidance. Journal of Child Psychology and Psychiatry, 55(7): 758-768.

O’Roak, B.J., Deriziotis, P., Lee, C., Vives, L., Schwartz, J.J., Girrirajan, S., Karakoc, E., MacKenzie, A.P., Ng, S.B., Baker, C., Rieder, M.J., Nickerson, D.A., Bernier, R., Fisher, S.E., Shendure, J., \& Eichler, E.E. (2011). Exome sequencing in sporadic autism spectrum disorders identifies severe de novo mutations. Nature Genetics, 43(6): 585-589.

Pearson, N.A., Patton, J.R., \& Mruzek, D.W. (2016). Adaptive Behavior Diagnostic Scale (ABDS). Austin, TX: ProEd.

Perry, A., Flangan, H.E., Geier, J.D., \& Freeman, N.L. (2011). Brief report: The Vineland Adaptive Behaviour Scales in young children with autism spectrum disorders at different cognitive levels. Journal of Autism and Developmental Disorders, 39(7): 1066-1078.

Pierangel, R., \& Giuliani, G. (2007). The Educator's Diagnostic Manual of Disabilities and Disorders (EDM). Hoboken, NY: John Wiley \& Sons.

Psychological Corporation (2003). Understanding sensory processing: An update/updating our understanding of sensory processing. Available from: http://images.pearsonclinical.com/images/PDF/UnderstandingSensoryProcessing.pdf.

Pugliese, C.E., Anthony, L., Strang, J.F., Dudley, K., Wallace, G.L., \& Kenworthy, L. (2015). Increasing adaptive behaviour skill deficits from childhood to adolescence in autism spectrum disorder: Role of executive function. Journal of Autism and Developmental Disorders, 45(6): 1579-1587.

Rapaport, J., Chavza, G., Addington, A., \& Gogtayn, D. (2009). Autism-Spectrum Disorders in Childhood and Schizophrenia: Clinical and biological contributions to a relationship re-visited. Journal of American Academy of Child and Adolescent Psychiatry, 48(1): 10-18.

Reber, M.E. (2012). Autism nosology: historical perspectives. In M.E. Reber (Ed.), The autism spectrum: Scientific foundations and treatment. Cambridge University Press. pp: 1-10.

Renfrew, C. (1998). The Renfrew Language Scales: Word Finding Vocabulary Test. Milton Keynes: Speechmark.

Rudy, L.J. (2018). Making sense of the 3 levels of autism: Levels of support included in an autism spectrum diagnosis. Available from: https://www.verywellhealth.com/what-are-the-three-levels-of-autism-260233?print.

Sandars, S.J., Murtha, M.T., Gupta, A.R., Murdoch, J.D., Raubeson, M.J., Willsey, A.J., Ercan-Sencicek, A.G., DiLullo, N.M., Parikshak, N.N., Stein, J.L., Walker, M.F., Ober, G.T., Teran, N.A., Song, Y., El-Fishawy, P., Murtha, R.C., Choi, M., Overton, J.D., Bjomson, R.D., Carriero, N.J., Meyer, K.A., Bilguvar, K., Mane, S.M., Sestan, N., Lifton, R.P., Gunel, M., Roseder, K., Geschwind, D.H., Devin, B., \& State, M.W. (2012). De novo mutations revealed by whole-exome sequencing are strongly associated with autism. Nature, 485(7397): 237241.

Saulnier, C.A., \& Klaiman, C. (2018). Essentials of Adaptive behaviour assessment of neurodevelopmental disorders. Hoboken, NJ: John Wiley \& Sons.

Schonell, F. (1955). Schonell Graded Word Spelling Tests (A \& B). London, UK: Oliver and Boyd.

Schonell, F.J., \& Schonell, F.E. (1950). Schonell Graded Reading Tests. London, UK: Oliver and Boyd.

Schonell, F.J., \& Schonell, F.E. (1952). Diagnostic and attainment testing. London, UK: Oliver and Boyd.

Schuster, M.A. (2000). Developmental screening. In E.A. McGlynn (Ed.), Quality of care for children and adolescents: A review of selected clinical conditions and quality indicators. Santa Monica, CA: RAND. pp: 157-168

Vol. 2, No. 1, pp. 13-35

2019

DOI: 10.53935/2641-533x.v2il.22

Corresponding Author: Sharon Jieren Wong

Email:wjsharon@gmail.com

Funding: This study received no specific

financial support.

Acknowledgement: The authors wish to thank the parents of CT for their kind permission to use and share the assessment results in this paper. Article History

Received: 5 December 2018

Revised: 31 December 2018

Accepted: 16 January 2019

Published: 13 February 2019

() 2019 by the authors; licensee Academic

Publishing Group

Shearer, E. (Ed.) (1972). Schonell Reading Tests-Revised (SRT-R). London, UK: Oliver and Boyd.

Sparrow, S.S., Cicchetti, D.V., \& Balla, D.A. (2005). Vineland Adaptive Behavior Scales-2 ${ }^{\text {nd }}$ Edition (VABS-2). Circle Pines, MN: American Guidance Service.

State, M.W., \& Sestan, N. (2012). The emerging biology of autism spectrum disorders. Science, 337(6100): 1301-1303.

Stone, J., Smyth, R., Carson, A., \& Warlow, C. (2006). La belle indifference in conversion symptoms and hysteria: Systematic review. The British Journal of Psychiatry, 188(3): 204-209.

Volkmar, F.R., \& Cohen, D.J. (1991). Comorbid associations of autism and schizophrenia. American Journal of Psychiatry, 148: 1705-1707. 
Vorstman, J.A., Breetvelt, E.J., Thode, K.I., Chow, E.W., \& Bassett, A.S. (2017). Expression of autism spectrum and schizophrenia in patients with a 22q11.2 deletion. Schizophrenia Research, 143(1):55-59.

Wechsler, D. (2003). Manual for the Wechsler Preschool and Primary Scale of Intelligence-Fourth Edition (WPPSI-IV). San Antonio, TX: The Psychological Corporation.

Worthy, J., \& Invernizzi, M.A. (1995). Linking reading with meaning: A case study of a hyperlexic reader. Journal of Reading Behavior, 27(4): 585-603.

Yuhas, D. (2017). Do schizophrenia and autism share the same root? Scientific American: Spectrum. Available from: https://www.scientificamerican.com/article/do-schizophrenia-and-autism-share-the-same-root/.

ZERO-TO-THREE (2016). Diagnostic classification of mental health and developmental disorders of infancy and early childhood (DC:0-5 ${ }^{\mathrm{TM}}$ ). Washington, DC: Author.

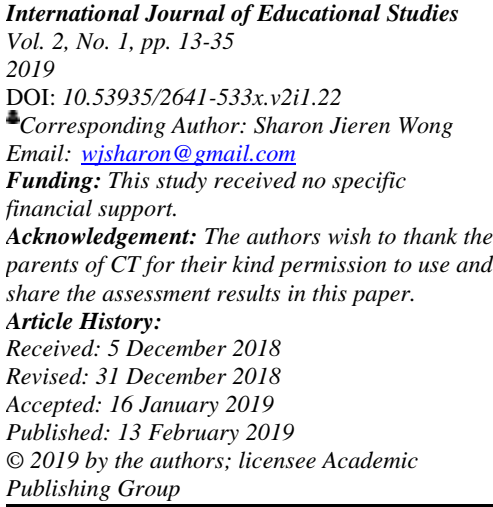

